

\section{Fatigue crack closure, observations and technical significance}

This report was presented as a keynote paper at the International Symposium on Faituge Crack Closure, 1-2 May 1986, Charleston

\section{J. Schijve}




\section{FATIGUE CRACK CLOSURE, OBSERVATIONS AND TECHNICAL SIGNIFICANCE}

$$
\text { J. Schijve }
$$

ABSTRACT: The meaning of crack closure for fatigue crack growth resistance is discussed under different headings.

(1) Mechanistic aspects of crack closure. Essential differences between microcracks and macrocracks. Microstructural influences.

(2) Direct methods and indirect methods to measure crack closure.

(3) Numerical aspects of crack closure relations for constant-amplitude loading.

(4) Crack closure and variable-amplitude loading.

The paper is an analytical study to summarize the present state of the art. Attention is paid to microstructural aspects, changing crack growth mechanisms under threshold conditions and $3-d$ aspects including plane strain/plane stress problems.

KEY WORDS: fatigue, crack growth, fatigue mechanism, crack closure, constantamplitude loading, variable amplitude loading, micro structure, survey

1) Professor, Department of Aerospace Engineering, Delft University of Technology, 2629 HS Delft, The Netherlands

\section{ABBREV IATIONS}

$C A$ constant-amplitude

VA variable-amplitude

OL overload

UL underload

CT .. compact tension

CCT center cracked tension
SUBSCRIPTS used for $S$ and $K$

op opening

cl closure

th threshold

eff effective

\section{INTRODUCTION}

The historical development of the present knowledge on fatigue crack initiation and fatigue crack growth is marked by a number of characteristic observations and analytical concepts. A brief listing should serve here to set the scope of the present paper.

Microscopical observations: The first observations on early crack initiation were made by Ewing and Humphrey in 1903 [1]. For a long time the optical 
microscope was the only apparatus to study fatigue crack growth. Later more detailed information could be obtained with the electron microscope (first TEM, now also SEM). Important fractographic studies could be made, and an outstanding feature was the discovery of striations, which indicated a cycleby-cycle crack growth mechanism.

Fatigue damage interaction effects: The prediction of fatigue life and crack growth under variable-amplitude (VA) loading is a well recognized engineering problem for years. The introduction of the servo-electro-hydraulic fatigue machine was a mile stone. It has generated a large amount of data on fatigue damage interaction effects. Progress is made in developing prediction models, but accurate and generally applicable engineering techniques are not yet available.

The stress intensity factor: The application of the stress intensity factor $(K)$ to fatigue crack growth under $\mathrm{CA}$ loading and to fracture toughness ( $\mathrm{K}_{\mathrm{IC}}$ ) is well established by now. The first paper on the correlation between the fatigue crack growth rate $d a / d N$ and $\Delta K$ was published 25 years ago by Paris, Gomez and Anderson [2].

Crack closure: Crack closure under cyclic tension was discovered by Elber in $1970[3,4]$. He proved the occurrence of plastic deformation in the wake of a growing fatigue crack by measuring a non-linear crack opening behaviour. It is surprising that the concept of crack closure under nominal tensile stress cycles was not recognized earlier. The situation now has drastically changed. It appears that no fatigue crack problem can be explained without considering crack closure. In the mean time other mechanisms for crack closure have been proposed, such as surface roughness, oxidation and crack bridging [5,6]. It is noteworthy that Endo, Komai and Ohnishi already in 1969 [7] explained a lower crack growth rate in rotating beam steel specimens if tested in salt water by referring to "wedge action caused by the metal oxide in cracks which reduced the strain amplitude at the crack tip".

Small cracks: The so-called small crack problem is associated with initially fast crack growth at nominally calculated $\Delta K$-ranges, which are significantly lower than a threshold value $\left(\Delta K_{t h}\right)$ observed for large cracks. The observation interferes with a generally applicability of $\mathrm{da} / \mathrm{dN}-\Delta \mathrm{K}$ relations to both large and small cracks. Apparently there are restrictions to the validity of fracture mechanics.

Threshold $\Delta K$-values: The existence of a threshold $\Delta K$-value required for the growth of a fatigue crack seems to be a physical realistic concept. Many experimental programs on threshold levels have been carried out in the last years, which revealed interesting effects of the materlal structure and the environment. 
If developments on the above topics are followed through the large amount of literature; a few trends emerge. From an engineering point of view the progress looks fairly slow. Secondly, fatigue is a complex process, which can be significantly different for different materials, environments and loading conditions. However, qualitatively an improving understanding can be noticed throughout the literature. Finally, our abilities to predict quantitatively the growth of fatigue cracks under variable-amplitude loading is still not yet satisfactory.

In the present paper it will be tried to survey problems involved in crack closure considerations, and to arrive at some conclusions as $f$ ar as that it is possible. Some comments on the technical significance of crack closure will be made first, followed by a discussion on mechanictic aspects of crack closure and on measuring techniques. Other topics of the paper are numerical aspects of crack closure relations for CA-loading, and the meaning of crack closure for the prediction of fatigue crack growth under VA-loading. It is hoped that the paper will contribute to the evaluation of the present understanding of crack closure and its practical-significance. A number of conclusions súmmarize the main observations.

THE TECHNICAL SIGNIFICANCE OF CRACK CLOSURE

The technical significance of crack closure is per definition related to the growth (or arrest) of fatigue cracks under service load histories. The ultimate goal is to obtain quantitative predictions on fatigue crack growth in terms of $\mathrm{mm}$ per year or some other service period. Such predictions are required for safety and economy reasons, e.g. for aircraft structures, pressure vessels, offshore structures, engine and power generator components, etc. Sometimes the service load time history is much similar to constant-amplitude (CA) loading (including a constant mean load as well), whereas in other cases a variable-amplitude (VA) load history is prevalent. In both cases quantitative knowledge of the crack opening stress level ( $s_{\text {op }}$ ) is generally believed to be essential for crack growth predictions, because:

(i) $S_{o p}$ is required to define $\Delta K_{\text {eff }}\left(=K_{\max }-K_{o p}\right.$, see Fig.1)

(ii) $\Delta K_{\text {eff }}$ is supposed to be the appropriate field parameter for correlating crack growth rates under different cyclic loading conditions.

The correlation of crack growth data starts from the similarity (similitude) approach, based on $\Delta K_{\text {eff }}$. Which predicts that equal $\Delta K_{\text {eff }}$-cycles will produce the same crack growth increments. The similarity thus should allow predictions on: 
- crack growth under CA-loading, in order to account for different R-ratios. - crack growth under VA-loading, in order to account for interaction effects (sequence effects).

The application of $\Delta K_{\text {eff }}$ to $V A$-loading requires a prediction on the variation of $\dot{S}_{o p}$ during a VA-load history, which for the more advanced prediction models implies a cycle-by-cycle prediction. Investigations on such models are still in progress. Anyhow, the prediction problems are the legitimate background for research on $S_{o p}$ and the applicability of $\Delta K_{e f f}$.

The above arguments on the application of $\Delta K_{\text {eff }}$ refer to quantitative predictions. Of course qualitative indications can be technically significant also. It can help to improve our understanding of the effects of several variables, which are of technical interest. As an example, some environmental effects can be understood by considering corrosion products in the crack tip, which can enhance crack closure and reduce $\Delta K_{e f f}$. It also can help to understand the effect of material variables on the fatigue crack growth resistance of different alloys and heat treatments.

The application of $\Delta \mathrm{K}_{\text {eff }}$ is condiderably complicated by two problems already mentioned in the introduction, viz. (1) small cracks and (2) threshold $\Delta K-$ values. Small cracks can be technically significant because in many cases a relatively large part of the (finite) fatigue life is spent in the small crack length regime. The threshold problem is particular relevant for fatigue under VA-load spectra, if the spectrum includes many "small" cycles. It then is important to know whether the small cycles do exceed a threshold $\Delta K-v a l u e$, and to which extent it will occur.

In view of all these practical problems it is of more than academic interest to know if predictions based on $\Delta K_{\text {eff }}$ and the similarity (similitude) concept can lead to satisfactory results. If useful correlations are not obtained it is better to understand why this is so. Three different arguments could be relevant.

(1) The similarity can be violated because the crack growth mechanisms are no longer similar.

(2) The crack can be too small for adopting $K$ as a unique field parameter.

(3) In addition to $\Delta \mathrm{K}_{\mathrm{eff}}$ and other conditions being nominally similar, it is possible that more crack tip aspects also affect crack growth, such as crack tip blunting, (cyclic) strain hardening, etc. It would imply a limitation to the uniqueness of $\Delta K$.

In view of the above questions crack growth and crack closure will be considered first from a mechanistic point of view. 
MECHANISTIC ASPECTS OF CRACK CLOSURE

A discussion on mechanistic aspects of crack closure has to start from basic information on fatigue mechanisms in materials. For fatigue predictions it is usual to consider two parts of the fatigue life:

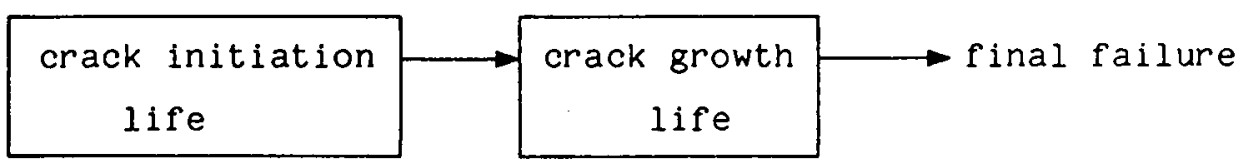

The crack initiation life includes (and largely covers) the microcrack growth period, whereas the crack growth life is supposed to represent the macrocrack growth period. An obvious question is: when does a microcrack become a macrocrack? One out of three definitions given in [8] is: A crack becomes a macrocrack if it has reached sufficient depth (or length) to be sure that local (surface) conditions, responsible for crack nucleation, do no longer affect crack growth. Further growth will then depend on bulk properties. Various differences between microcracks and macrocracks indicated in [9] are recapitulated here in table 1. Apparently there are several arguments to explain differences between the mechanisms for both types of cracks. Moreover different arguments may apply to different materials. As a consequence there is no single numerical value for the transition crack length between microcracks and macrocracks. A value of about $100 \mu \mathrm{m}$ (or less) could apply to several Al-alloys, whereas a value of $1 \mathrm{~mm}$ (or more) might be more realistic for $\mathrm{Ti}$ - and Ni-alloys with. a coarse micros'tructure.

\section{Aspects of crack nucleation and microcracks}

Microscopical investigations on crack nucleation and early microcrack growth have been made on several materials, while a considerable amount of work was done on Al-alloys. In many alloys microcracks are nucleated at intermetallic particles or other material defects. In purified Al-alloys microcracks;can also start in slipbands, whereas in some other materials nucleation occurs at grain boundaries. The general trend is that the number of microcracks increases if the fatigue load is higher. Nevertheless, it is still remarkable that the number of microcracks observed is relatively small if compared to the number of grains at the material surface where nucleation could occur. Usually there are more than 100 grains in one $\mathrm{mm}^{2}$ of the surface. It implies that the few grains where crack nucleation starts must have some special features. If crack nucleation in an Al-alloy starts at an intermetallic particle $(1-10$ $\mu \mathrm{m})$ significant aspects should be the size, the shape and the location of the particle within a grain, as well as its composition and interface 
characteristics. The same applies to the grains where nucleation occurs, their shape, size and lattice orientation will be important. These aspects have a significant influence on the stress distribution on a micro level. "Micro stress concentrations" will be further enhanced by the elastic anisotropy of the material, which is relatively small for Al, but more significant for Fe, $\mathrm{Cu}$ and Ni-alloys. Helle [10] studied the statistical distribution function of the resolved shear stress in grains of a polycrystal finite-element model of a Cu-5\%Al alloy. He found the distribution function to be approximately normal with a standard deviation of about $20 \%$ of the mean value. Although Helle had to adopt some simplifications in his model the results do indicate that a small number of grains will carry a significant larger stress than the average value. In other words, the stress distribution from grain to grain can be rather inhomogeneous, depending on the type of material.

Moreover it should be realized that the resistance against cyclic slip at the free surface will be less (table 1) due to the lower constraint on plasticity. Neighbouring grains are missing on one side. The constraint argument will also have some significance for the crack opening of the very first microcrack. The conclusion here is that there are several unfavourable conditions on a micro level, which apply to the grains in which the first microcracks are nucleated. Secondly some of these conditions will also contribute to an initially fast growth of the first microcrack, and thus contribute to the so-called small crack problem.

The effect of grain boundaries on the growth of a small microcrack is another consequence of the polycrystalline nature of materials. Also here most observations were obtained for Al-alloys. It appears that the growth rate of a microcrack still contained within one grain, decreases when the crack tip comes near to the grain boundary [11-14]. In view of the restraint of the grain boundary on cyclic slip this seems to be a natural result. After crossing the grain boundary the microcrack has to grow in a grain with a different lattice orientation. This could well imply another obstruction to microcrack growth. Lankford [13] obtained fractographic evidence of a "renucleation" process at the other side of the grain boundary. Illustrative data on highly reduced crack growth rates near the grain boundaries, not only of the first grain, but of a few more, have recently been published by Blom et al [14].

After the crack size becomes larger than just a few grains, the crack front will be moving in several grains. The ratio: 
(see table 1) will increase. As long as the ratio is small, grain boundaries will cause discontinuous crack growth. Once the ratio is large such discontinuities can still occur locally, but the "average" growth becomes a more continuous process.

Highly reduced growth rates after an initial fast growth of the first microcrack were also observed in other materials, where the obstacles could be pearlite colonies in steel [15] or grain boundaries and grain boundaries deflections in a $\mathrm{Ni}$ based super alloy [16].

The question of crack closure of microcracks got some attention in the literature. It may well be expected to occur because of microplastic deformations and mismatch between the crack surfaces. Nisitani and Takao $[17,18]$ made microscopical observations on crack opening of microcracks in C-steel. At $S_{\max }$ an arrested microcrack was still closed at the very tip of the crack, whereas a growing one was open at the tip. Lankford, Davidson and Chan [19] observed crack closure of microcracks in 7075-T6 tested in a SEM. A similar observation was made by Morris [20] on microcracks in 2219-T851.

on the other hand, the material conditions controlling the initial microcrack growth are essentially different from those applying to the macrocrack growth phenomenon as it occurs later on. It then cannot be expected that similar relations for $S_{o p}$ (and $K_{o p}$ ) will hold for both microcracks and macrocracks. Keeping in mind the definition of the microcrack given before, the conclusion to be reached is: Essential differences between the crack growth mechanisms of microcracks and macrocracks preclude a simple correlation between the growth rates of the two types of cracks. Such a conclusion was already mentioned by Lankford et al [19]

If a correlation had been justified from a mechanistic point of view, it still would be questionable whether $\Delta K$ or $\Delta K_{\text {eff }}$ can be used for such a correlation. If a crack size is very small the meaning of $K$ as a relevant field parameter becomes debatable for wellknown fundamental reasons. Linear elastic fracture mechanics should no longer be used in such a case. Then a more relevant field parameter appears to be the local stress or strain cycle.

Note: The last comment does not necessarily apply to small cracks at the root of a notch, which are known for an initially high growth rate. Such cracks are not really microcracks. The initially fast growth occurs because a plastic wake field has not yet been built up [9]. As a result $\Delta K_{\text {eff }}$ is higher than it would be at the same $k$-value for a longer crack. Newman [21] made finiteelement calculations on this phenomenon and he found good agreement with experimental observations from different sources in the literature. These 
small cracks were labelled in [22] as "mechanically short" cracks, whereas the microcracks discussed before were indicated by Ritchie and Suresh [23] as "microstructural short" cracks. The main aspects of the two types of cracks are summarized in table 2.

\section{Crack closure of macrocracks}

Crack closure implies material contact between the upper and lower surface of a fatigue crack with load transmission through the contact area. It is now. generally understood that it can occur under tensile loading because of different reasons as discussed by Ritchy and Suresh [5]:

(1) plastic deformation in the wake of the crack (plasticity induced crack closure, Elber mechanism).

(2) a mismatch between the two crack surfaces, due to surface roughness, asperities, crack branching, mixed mode crack opening, etc.

(3) crack surface oxidation.

The first ideas about crack closure mechanisms were postulated by Elber $[3,4]$. He assumed the crack to be fully or partially closed at positive minimum stresses, due to a surplus of plastic deformation in the wake of the crack. During an increase of the load a continuous unfolding of the crack flanks will occur until the crack is fully open at $S=S_{\text {op }}$ (see Fig.2). From then on a further increase of the load will theoretically cause a "singular increment of the stress intensity at the crack tip. Elber defined the effective stress range as:

$$
\Delta S_{\text {eff }}=S_{\text {max }}-S_{\text {op }}
$$

which he introduced in the effective WK-value as:

$$
\Delta K_{\text {eff }}=c \Delta S_{\text {eff }} \sqrt{\pi a}
$$

( $C$ is the geometry correction factor). Upon unloading crack closure, starting at $S=S_{C l}$ is also a continuous process. The plasticity induced crack closure as outlined in Figure 2 suggests a 2-dimensional mechanism for a through crack. Unfortunately it is complicated by 3-dimensional aspects. Two macroscopical 3-dimensional features should be mentioned here:

(i) plane strain/plane stress transition along the crack front, (ii) shearlips at the surface of the material.

\section{Plane strain/plane stress}

For a through crack in a thick plate it is usually assumed that the crack front is largely in a state of plane strain $\left(\varepsilon_{z}=0\right)$, if the fatigue load is not too high. This is due to the lateral constraint on deformations in the zdirection (thickness direction). Near the surface of the plate, plane stress 
conditions will prevail because $\sigma_{z}=0$ at the surface. First order approximations of the plastic zone size are given by:

$$
r_{p}=\frac{1}{2 \alpha \pi}\left(\frac{k}{\sigma_{y i e l d}}\right)^{2}
$$

The factor $\alpha$ depends on the relevant state of stress. Realistic estimates for $\alpha$ appear to be $\alpha=3$ for plane strain and $\alpha=1$ for plane stress. Although such estimates ignore the shape of the plastic zone, they reflect the different zone sizes. Pictures as shown in Figure 3 were published by Liu [24] and Dixon [25], and repeated later in other publications. The implication is that the larger plastic zone size near the outer surface of the plate should lead to more crack closure near the surface. As a result the ends of the crack front at the surface will trail behind the major part of the advancing crack front. Slightly curved crack fronts are a wellknown phenomenon. Observations on trailing ends are more common for semi-elliptical surface cracks or quarter-elliptical corner cracks, especially under VA-loading with occasionally high loads. An example is shown in Figure 4.

Actually the above picture on plane strain/plane stress differences along the crack front is rather simplistic. First, the large differences between the plane stress and the plane strain plastic zone sizes (suggested by $\alpha=1$ and $\alpha$ =3) will occur only if both plastic zones can develop independently. However, because of the continuity of the material this can not freely occur. Consequently the plastic zone sizes will vary significantly less along the crack front. The plastic zone size in the plane stress surface area will be smaller than expected from a $2-d$ plane stress situation, and the tensile stress will also be smaller than expected. Second, in the plane strain plastic zone higher tensile stresses are present because of the higher effective (von Mises) yield stress. That might cause faster crack growth in the plane strain part of the crack front, which is a different reason for a curved crack front. Third, in the plane stress surface zone larger deformations can be accommodated before fracture. Especially under VA-loading this could be significant. The free surface effect can be understood in qualitative terms, but it should be admitted that simple quantitative evaluations will remain speculative.

Shear lips

The development of shear lips (Fig.5) is a wellknown phenomenon for Al-alloys, but is has been observed for some other materials as well. It implies a mixed 
mode I/III crack opening. The shear lips are usually associated with plane stress conditions at the surface. However, such a simple and unique correlation is not as plausible as it appears to be. It was shown [27] for Al-alloys that the shear lip width is smaller in an aggressive environment, which macroscopically postpones the transition from the tensile mode to the shear mode (Fig.6) to a larger crack length (or a higher $\Delta K$-value). An inert environment promotes the formimg of shear lips and the transition to the shear mode failure. Apparently the environment, by its influence on the fracture mechanism, also affects the shear lip width. It was explained in [27] by referring to a competition between tensile decohesion and shear decohesion, where tensile decohesion is promoted by a high tensile stress and an aggressive environment. Shear decohesion is promoted by a high shear stress and the absence of an aggressive environment. At the material surface $\varepsilon_{y}$ is smaller than expected, whereas shear stresses with a component in the Z-direction are considerably higher (appendix $B$ of [29]). As a result the free surface will promote a shear mode failure, whereas an aggressive environment will promote a tensile mode failure.

(It is interesting to note that the faster crack growth in the aggressive environment is partly due to the lower crack growth resistance in that environment. However, another contribution is due to the smoother fracture surface of the crack, which implies a higher crack driving force).

The failure mechanism in the tensile mode occurs cycle-by-cycle as shown by fatigue striations. Although striations are not observed in the shear lips (except in Al-cladding layers [29]), a cycle-by-cycle mechanism will still apply. In relation to crack closure shear lips should be supposed to be the first part where mating crack surfaces will touch during unloading. The black corrosion debris on the shear lips of Al-alloy fatigue fracture surfaces are proof of this cyclic contact. Lindley and Richards [30] have shown for mild steel that closure contacts start at the shear lips. Apparently the permanent plastic deformation is larger for the shear lips than for the tensile mode area of the fatigue fracture. The contribution of shear lips to crack closure was indicated by Ewalds and Furnee [31]. They reduced the thickness of plate specimens with a fatigue crack in order to remove the shear lips. As a result the crack closure stress level was reduced. Another proof was given by McEvily [32]. He found a significant crack growth delay after an overload (Al-alloy). A much smaller delay was found if the thichness was reduced immediately after the overload. Shear lips are an unfortunate 3 -d aspect of crack closure, but they are real and relevant. 
Contacts between the two fracture surfaces during crack closure

Crack closure as sketched in Figure 2. suggest a perfect fit between the mating fracture surfaces. In reality the contact will have a more complex nature. The shear lips discussed before are complicating the contact near the surface. However, considering the tensile mode fracture only, a perfect $f i t$ should still not be expected. Macroscopically flat fatigue fractures are not at all flat on a micro level, because various inhomogeneities of the material structure will affect the growth process. Microscopical growing directions will vary along the crack front. Depending on the type of material there is a variety of relevant structural features, such as grain boundaries, lattice orientation in different grains (especially if a pronounced texture is present), inclusions, $\alpha-\beta$ phase boundaries in Ti-alloya, pearlitic colonies in steel, etc. A tortuous crack path will be the result, with a possibility for crack branching. On a micro level it should lead to an irregular crack front topography. A perfect fit of the mating surfaces appears to be fully illusive.

Bowles $[33,34]$ developed the vacuum infiltration method to obtain plastic castings of the crack itself. Fatigue cracks in 2024-T3 could still be infiltrated at $S_{\text {min }}(R=0.33)$. The casting showed that crack closure occurred only at discrete locations of maximum mismatch between the fracture surfaces. It was concluded that the major part of the crack remains microscopically open, which explains that tire tracks are rarely observed. It should also be noted that striations on Al-alloy fractures are usually visible on the larger part of the fracture surface. These observations should not be expected after numerous cyclic closure contacts if a perfect mating fit was always obtained.

\section{Structurally sensitive macrocrack growth and crack closure}

The microscopical roughness of the fracture can depend on the severity of the cyclic laod. An illustrative example was published by Stubbington and Gunn [35]. A test on a CT specimen of a Ti-6Al-4V alloy at a low fatigue load produced "structural sensitive cracking" on preferred cryctal planes. A fairly coarse surface morphology was obtained. At higher fatigue loads a relatively flat structure insensitive crack plane was found. The $K_{I c}$ for the flat fracture surface was about 1.5 times lower than for the coarse fracture surface. Crack driving forces do apparently depend on the detailed topography of the fatigue fracture surface.

In some recent work fatigue fracture surfaces of 2024-T3 specimens, which had been loaded under flight-simulation loading, were examined [unpublished]. 
After the severest flights crack growth was significantly slower. The fracture surface then shows macroscopically dark bands. Partly it is due to some quasi static crack extension during the maximum load of the severe flight. However : the main cause is a kind of rubbing debris, produced during delayed crack growth after the severe flights. Microscopically the fracture surface after a severe flight becomes very rough and irregular. Broken or torn out intermetallic particles contribute to a tortuous crack path. The observations clearly suggest that the crack closure contacts will be significantly different from what it would be under CA-loading. Suresh [36] discussed the fracture surface roughness during delayed crack growth after an overload. He mentiones the tendency to stage I crack growth in this period. Lankford and Davidson [37] observed crack growth after an overload in the SEM. Crack branching and growth in a deviating direction (i.e. in the direction of the slip zones) was observed on the specimen surface during the retarded growth period.

The above evidence indicates that slow crack growth after a high load can be different from slow crack growth in CA-tests, depending on the material structure. Structual sensitive macrocrack growth attracted a lot of attention in. crack growth threshold studies, also because of possible practical applications (see e.g. [38]). Major effects on $\Delta K_{t h}$ are due to the stress ratio $R$, the environment and the material structure. From a mechanistic point of view it might appear reasonable that crack extension in a cycle requires $k_{t h}$ to be somewhat higher than $K_{o p}$ (see Fig.1). An experimental verification, however, is not easy. Threshold $\Delta K$-values are generally determined by careful WKdecreasing procedures (load shedding) to avoid load history effects. Nevertheless, measurements during such tests have shown a steadily increasing $S_{\text {op }}$ [39-42]. Illustrative examples obtained by Minakawa and McEvily [39] are, shown here in Figure 7. Such results suggest that crack arrest is a conse-" quence of $S_{o p} / S_{\max }$ going to 1 , which did occur for the two Al-alloys. Calculations of Newman [21] support the idea that thresholds are associated with $\Delta K_{\text {eff }} \rightarrow 0$, but he assumed that plane stress conditions were applicable in controlling the growth of the crack. Although some history effect may well raise $S_{o p}$ during $\Delta K$-decreasing tests, the assumption of plane stress seems to be unrealistic. Minakawa and McEvily explained the increase of $S_{\text {op }}$ by refer$r$ ing to combined mode I and mode III opening. There are more indications from some investigations which show that the crack growth mechanism at a very low growth rate deviates from the growth phenomenon at high growth rates $[39,43,44]$. A tendency to grow along crystallographic planes is observed, which unavoidably must lead to geometrical incompatibilities in a polycrystalline material [9]. In order to maintain a coherent single crack front from grain to grain, crack branching and other complex failure modes should be expected. 
If crack growth occurs at an extremely slow growth rate it implies that the crack driving force is marginal. Under such conditions the number of operative slip systems will be small. If only one slip system is predominantly' contributing to crack growth, crystallographic cracking (stage I) will occur. On a micro level crack growth will then become more structurally sensitive because of local barriers to cyclic slip and the crack front coherency aspects mentioned before. The possibilities of crack surface mismatch, interacting opening modes, rubbing and oxidation will increase. It implies that more crack closure will occur, better to say, that more complex microcrack closure mechanisms will contribute. As a result the crack growth rate will still further decrease and crack arrest seems a logical result. Apparently there are synergistic activities: a changing growth mechanism causes more crack closure, and more crack closure reduces the crack driving force, which leads to a further change of the growth mechanism. Under such conditions it should be expected that $\Delta K_{\text {eff }}$ will approach zero.

crack arrest need not occur in all materials in this way. It will depend on the question whether crack growth at low rates is that much sensitive to the material micro structure, that it will change the growth mechanism. If not, a small positive $\Delta K_{t h \text {, eff }}$ could be possible. James and Knott [45] recently published $\Delta K_{t h}$ measurements for a NiCrMo-steel (HY80). Precracked specimens were stress releaved after which $\Delta K_{t h}$ was determined in stepwise $(5-7 \%) \Delta K$ increasing tests. They found an approximately constant value for $\Delta K_{t h, e f f}$ ( 3 $M P a / m$ ) for $R$-values from 0.2 to 0.7 .

\section{METHODS TO MEASURE CRACK CLOSURE}

A survey of the various methods is given in table 3. It shows the principles to observe the occurrence of crack closure, which can be used to measure $S_{\text {op }}$ (and/or $\mathrm{S}_{\mathrm{cl}}$ ). Three main groups are labelled as:

(1) direct observation of crack closure at the crack tip,

(2) compliance measurements based on a virtual change of crack length during crack closure, and

(3) indirect methods based on crack growth measurements as affected by crack closure.

Several comments on these methods are made below. It should be pointed out that $S_{o p}$ and $S_{c l}$ can be different. For the mechanical compliance methods it is sometimes preferred to measure $S_{c l}$ during the unloading part of a load cycle, because a better defined inflection point can be observed on the P-COD record. For physical reasons we should be more interested in $S_{o p}$, but the difference between $S_{o p}$ and $S_{c l}$ is small and perhaps negligible. This question will not further be addressed here. 
The most direct observation of crack closure is to study the fatigue crack through the microscope during cyclic loading. Staal and Elen [46] adopted an optical microscope with a TV camera. They observed opening and closing of a fatigue crack (in 304 stainless steel) on a monitor with a maximum amplification of $800 \mathrm{x}$ on the screen. Larger magnifications can be obtained in a scanning electron microscope (SEM). It has been used with speciàlly designed small testing equipment to apply cyclic loads on a specimen in the SEM [47]. observations on crack tip profiles can also be made with the replica technique, but then a number of replica's is required to arrive at a crack opening stress level. Nisitani and Kage [48] have adopted this method for small cracks. They applied artificial scratch markings under $45 x$ with the crack growth direction to facilitate accurate measurements of the crack opening. For a growing crack the crack tip is fully open at $S_{\max }$, whereas for a non-propagating crack the crack tip appeared to be closed "so far as can be seen" (quoting from [48], replica observations in the electron microscope). A similar remark was made by Shin and Smith [49], who said;"it can not be deduced conclusively when the crack surfaces are actually touching and bearing the load".

Other ingenious measuring techniques were developed to observe displacements around the crack tip during cyclic loading. Davidson et al [50] introduced the stereoimaging technique on pictures obtained in a SEM. Optical interferometry was adopted by other investigators $(e .8 .[51,52])$. In addition to information on displacements fields such methods can also give indications on plastic deformation around the crack tip and on plastic zone size and shape. Davidson and Lankford observed mixed mode. I and II displacements leading to asymmetric plastic zones. The asymmetry was also observed by Nowack et. al [53]. If plastic zones are still small the asymmetry is not too surprising in view of the crystalifine nature of the material. It could be enhanced by free surface effects on local plasticity (lower restraint). Another obvious reason for asymmetric plastic zones at the surface is associated with shear lips. Such considerations emphasize the question about the relevance of surface observat.ions for the entire crack front.

A three-dimensional (3-d) picture about crack closure can be obtained by testing tranparant material [54,55]. Ray, Andrew and Grandt [55] carried out crack growth test on polycarbonate under constant-amplitude (CA) loading and under $\mathrm{CA}$-loading interrupted, by an overload (OL). Interferometry revealed that the crack opening stress level was relatively high at the surface, while it decreased at the interior of the material with a minimum at mid thickness. 
This was true before and after the OL, although the OL decreased the crack opening stress level directly after the $\mathrm{OL}$.

\section{Compliance measurements}

These methods are essentially based on measuring the variation of the compliance of a (virtually) increasing crack length. Such methods are used for automatic crack growth measurements [56]. Elber [4] used a clip gage (CODmeter) which he located $2 \mathrm{~mm}$ behind the tip of the crack. The distance of the clip gage or the strain gage to the tip of the crack is mentioned as a special feature in table 3. A popular position for a clip gage is at the center line of a center cracked tension specimen, or at the load line of a CT specimen. The advantage is that it has not to be replaced when the crack is growing. A similar argument applies to the so-called back face strain gage on a CT specimen. On the other hand, it has been stated that more accurate measurements can be made if the gage is positioned more close to the crack tip in view of the larger apparent change of the compliance. Some authors, however, have warned against a location too close to the crack tip, because of crack tip plasticity, which might lead to misleading results.

Accurate mechanical compliance measurement should be possible if sophisticated means are used to avoid spurious sources of hysteresis. Attachments of clip gages to specimens can be suspect in this respect. The sensitivity of the measurement can be increased by an electrical compensation of the CoD-signal by the linear part obtained for the open crack. Baik, Hermann and Arsaro [57] have claimed a very.high accuracy of $0.01 \mathrm{~mm}$ on crack length, which might well be the best result to be obtained with mechanical clip gages.

Strain gages bonded over the crack are bridging the crack opening. It has been said to be a rather sensitive method, although it appears a crude way of using a strain gage. It can not be used during continuing crack growth.

A completely different method was developed by Fleck and Smith $[58,59]$. In a relatively thick CT specimen $(24 \mathrm{~mm})$ two small holes $(1.5 \mathrm{~mm})$ were $\mathrm{drill}$ ed at mid thickness, parallel to the loading direction, just behind the crack front. The depth of one hole terminated $1 \mathrm{~mm}$ above the crack; and the other hole went a bit further until $1 \mathrm{~mm}$ below the crack. With a push-rod compliance gage the COD can then be measured through the holes at mid thickness. It indicated a lower crack closure stress level than observed at the outside on the specimen surface. This is another indication of the 3-d effect discussed before.

The electrical potential drop method is succesfully applied for automatic crack growth monitoring in fatigue tests. However the measurements have: to be made at a moment of a load cycle when the crack is definitely fully open. The 
experience with the potential drop method for measuring crack closure is not encouraging. Bachmann and Munz [60] indicated the significance of oxide layers on the fracture surfaces, which can act as an insulator. Moreover asperities may cause elctrical short-circuiting, which also leads to false indications. Apparently an electrically open (or closed) crack is not the same thing as a mechanically open (or closed) crack.

The application of the eddy current method to measure crack closure was reported by Lal, Garg and LeMay [61]. The eddy current probe was in close proximity to the crack tip. There is some control on the depth of penetration of the eddy currents by adjusting the frequency. The possibilities have not yet been fully explored, but arguments against the potential drop method might apply to this method as well.

Ultrasonic surface wave probes were adopted by Buck et al [62]. The acoustic tránsmission of these waves through a crack was supposed to indicate whether closure is present. It is not expected to be a very accurate method in $v i e w$ of uncertainties about the equivalence of acoustically closed cracks and mechanically closed cracks.

Indirect observations based on fatigue crack growth

Modern prediction models for crack growth under VA-loading assume that crack growth in a specific load cycle will not occur if:

$$
S_{\max } \leqq S_{\text {op }}
$$

The assumption has been used by Dekoning [63] to derive $S_{\text {op }}$ from crack growth results of fatigue tests with simple load histories. He applied the method to determine $S_{o p}$ an overload or an overload/underload cycle in a CA test. The principle is explained here for another load sequence, see Figure 8 . A number of tests has to be carried out with $S_{\max }$ of the second block of cycles as the variable. The maximum value of $S_{\max , 2}$, which does not lead to further crack growth, is supposed to be equal to $S_{o p}$ associated with the first block. The rationale is that crack growth should not be expected if the load in the first cycle of the second block does not exceed the $S_{o p}$ pertaining to the last cycle of the first block. The method assumes that the smallest amount of crack tip opening is sufficient for further growth. In other words:

$$
\mathrm{K}_{\mathrm{th}}=\mathrm{K}_{\mathrm{Op}}
$$

(Fig. 1). Even if this would not be true the stress level determined might be the relevant one for prediction methods. A disadvantage of the method is the fairly extensive experimental effort required.

Striations on fatigue fracture surfaces are easily recognized as the most direct evidence of crack growth in individual cycles. Striations may thus give 
information on $\Delta \mathrm{K}_{\text {eff }}$. Pelloux et al [64] performed tests with two types of load sequences as shown in Figure 9 (2124-T351,CTS). In each type 10 smaller cycles were introduced. Different $S_{\min }$ values were applied in the first type. When the striation spacings of the small cycles and of the large cycles were equal, it was concluded that $S_{\text {min }}$ of the small cycles is equal to $S_{\text {op }}$ of the larger cycles. The results indicated a fairly low $S_{o p}\left(=0.2 S_{\max }\right)$. The aim of the second type of load sequence is to increase $S_{\max }$ until striations of the small cycles turn up in the EM. That stress level was then supposed to exceed $S_{\text {op }}$ of the larger cycles. The few results, indicating very high $S_{\text {op }}$ values, were considered to be inconclusive due to the low number of small cycles.

Sunder and Dash [65] improved the above method by repeating load sequences as shown in Figure 10. $S_{\max }$ was kept constant, but $S_{\min }$ was varied periodically. The width of the individual striations was measured. For the larger cycles a constant striation width was found and for all these cycles it was supposed that $S_{\text {min }} \leqslant S_{o p}$. Values of $S_{o p}$ derived in this way were in the order of $S_{o p}=$ $0.35 \mathrm{~S}_{\max }$ for a $3 \mathrm{~mm} 2014-\mathrm{T} 3$ type alloy. For $5 \mathrm{~mm}$ thickness (same material) the results were:

$$
\begin{aligned}
& 0.14<\mathrm{s}_{\mathrm{op}} / \mathrm{S}_{\max }<0.21 \text { at mid thickness } \\
& 0.35<\mathrm{S}_{\mathrm{op}} / \mathrm{S}_{\max }<0.43 \text { at the surface. }
\end{aligned}
$$

This is another indication of more closure at the surface. A similar observation was mentioned by Pelloux et al [64] $(t=12.7 \mathrm{~mm})$.

It should be noted that for the above striation methods some a priori knowledge on crack closure during VA-loading was used. It was assumed that $S_{\text {op }}$ was constant for a short period with a small number of cycles. In the following method another assumption is made. The crack is supposed to remain fully open during a cyclic load at a high R-ratio. It was already observed in many investigations, that $U\left(=\Delta K_{\text {eff }} / \Delta K\right)$ becomes larger for higher $R$-values. Socalled cut-off values of $R$ beyond which no crack closure occurs, have been mentioned in the literature. For such high $R$-values

$$
S_{\text {op }}<S_{\min } \text { and } \Delta K_{\text {eff }}=\Delta K
$$

Crack growth results obtained at such high $R$-values should directly give the correlation between $d a / d N$ and $\Delta K_{\text {eff. }}$. It was recently adopted by zhang et al [66] who assumed that cracks remain fully open at $R=0.8$. These results were then adopted as a calibration to obtain $\Delta \mathrm{K}_{\text {eff }}$ at lower $\mathrm{R}$-ratios. The method is shown in Figure 11. $S_{o p}$ can be calculated from $K_{o p}=K_{\max }-\Delta K_{\text {eff }}$. An apparently excellent correlation between $d a / d N$ and $\Delta K_{\text {eff }}$ was obtained, but it should not be overlooked that this is largely a consequence of the $\Delta K_{\text {eff }}{ }^{-}$ calibration procedure (Fig.11). 
Some general impressions obtained from the literaure are summarized below:

(1) The occurrence of crack closure under tensile load is generally confirmed. However, it appears to be far from easy to get an accurate and unambiguous indication on the stress level, at which either full crack tip opening is obtained or crack tip closure just begins. Visual observations should give the most direct evidence, but it appears to be difficult, also at large magnifications, to decide at which moment the crack is closed. Moreover, it is a surface observation.

The mechanical compliance methods are generally thought to be superior to other ones, although there is no general agreement which of these methods gives the better results. Even the question of measuring at a location close to the crack tip or at some distance remote from the crack tip did not receive an unanimous answer.

(2) Some authors have stated that a back face strain gage on a CT specimen will give a "global" $S_{\text {op }}$ whereas a strain gage close to the crack tip on the specimen surface will indicate a local $S_{\text {op }}$ relevant to the plane stress surface layer only. Theoretically this argument is questionable because any nonlinear compliance should be detectable, wherever the compliance is measured. Only by a reduced accuracy local surface effects may remain undetected. This reveals a rather pertinent question: which $S_{\text {op }}$ do we want to measure? The question will return later.

(3) Retarded crack growth of overloads ( $O L$ ) are frequently explained by referring to crack closure effects. The explanation may not be as straight forward as it 'is in a 2-d model taking into account plasticity induced crack closure only, because of the changes of the growth mechanism discussed before. Unfortunately, crack closure measurements after the $\mathrm{OL}$, when the crack is slowly penetrating into the ol plastic zone, meet with extra accuracy problems. This is illustrated in Figure 12. The question is whether a compliance difference between $C\left(a_{O L}\right)$ and $C\left(a_{O L}+\Delta a\right)$, with $\Delta a / a_{O L}$ very small, can be detected. During a CA-test small crack length differences can detected by compliance measurements. However, in this case $S_{\text {op }}$ for opening the last minute bit of the crack length $(\Delta a)$ will be relatively high. As long as $\Delta a$ is very small an accurate determination of $S_{o p}$ for opening the last minute bit of the crack length $(\Delta a)$ will be relatively high. As long as $\Delta a$ is very small an accurate determination of $S_{o p}$ will be very difficult. It requires some more crack'growth before a double linear graph will reveal the true $s_{\text {op }}$ at the crack tip. An example of a compliance measurement with more than one linear part is shown in Figure 13. Systematic observations on crack closure after an OL were published by Paris and Hermann [68]. 
NUMERICAL ASPECTS OF CRACK CLOSURE RELATIONS

In the literature some equations were proposed to account for the R-effect on crack closure. Usually the equations were based on empirical results, but analytical studies were reported also. In some studies the equations were required for VA-predictions models. Elber [4] published the first quantitative data on crack closure for 2024-T3 sheet material. He arrived at the empirical relation:

$$
U=\Delta K_{e f f} / \Delta K=0.5+0.4 R \quad(-0.1<R<0.7)
$$

It is noteworthy that in this relation $U$ is independent of $K_{\max }$ and the crack length. The equation has apparently stimulated others to obtain similar $U(R)$ relations for other alloys and a wider R-range. Examples are given below as an illustration.

$\begin{array}{lll}2219-T 851 & U=0.68+0.91 \mathrm{R} & \text { [69] } \\ \text { Ti-6Al-4V } & U=0.73+0.82 \mathrm{R} & {[69]} \\ 7175-\mathrm{T} 651 & U=0.4+0.4 \mathrm{R} & {[70]} \\ 2024-\mathrm{T} 3 & U=0.55+0.33 \mathrm{R}+0.12 \mathrm{R}^{2} & {[71]} \\ \text { mild steel } & U=0.69+0.45 \mathrm{R} & {[72]} \\ \text { mild steel } & U=1 /(1.5-\mathrm{R}) & {[73]} \\ 7475-\mathrm{T} 73 & U=0.618+0.365 \mathrm{R}+0.139 \mathrm{R}^{2} & \text { [66] }\end{array}$

The equations look quite different. It is more instructive to see the relation between $\gamma=S_{o p} / S_{\max }=K_{o p} / K_{\max }$ and the stress ratio $\mathrm{R}$ in a $\gamma-\mathrm{R}$ plot, as shown in Figure 14. With:

$$
Y=1-(1-R) U
$$

and the above $U(R)$ equations the results obtained are plotted in Figure 15. The lines have been drawn as $f a r$ as they are covered by test results. A few trends are obvious: (1) There is a large spread in the stress opening stress levels, and (2) for most materials a steadily increasing $S_{o p}$ is found for an increasing $R$-value.

In view of different $\Delta K_{\text {eff }}$-results a conclusion drawn in [8] should be recalled here. Assume that $\Delta K_{\text {eff }}=U(R) . \Delta K$ with $U(R)$ obtained from test results, gives a satisfactory correlation between da/dN data obtained at different $R$-values. If we now define

$$
\Delta K_{e f f}^{*}=q \cdot \Delta K_{e f f}
$$

where $q$ is an arbitrary constant, $\Delta K_{\text {eff }}^{*}$ will equally well correlate the crack growth data. In a da/dN- $\Delta K_{\text {eff }}$ plot it implies that all data points will make the same horizontal shift defined by the factor $q$. That leaves the correlation unaffected. In Figure 14 the two dotted lines are obtak from the full line by employing $q=0.7$ and $q=1.32$ respectively. Aly three lines will equally well correlate crack growth data of different R-values, although they represent highly different crack opening stress levels. frictly speaking, it 
implies that a satisfactory correlation of crack growth data does not necessarily prove that the correct $S_{o p}$-stress levels were obtained.

The above considerations apply to the Paris crack growth regime (Fig.16). Correlations based on crack closure are more problematic for the threshold regime as a consequence of structurally sensitive crack growth discussed before. At the other end of the graph, the static failure mode regime, the simple Elber assumptions also break down, i.e. $K_{\text {op }}$ is no longer independent of $\mathrm{K}_{\mathrm{max}}$ and the crack length. The independence of the crack length never was a
topic of great concern, probably because it was thought to be well accounted topic of great concern, probably because it was thought to be well accounted for by $k_{\max }$. In this respect an early observation should be recalled. Crack growth rates obtained in $\mathrm{K}$-increasing tests (e.g. CCT specimen under CAloading) and in in $K$-decreasing tests (by crack edge loading) indicated a similar da/dN- $\Delta K$ relation $[74,75]$. As shown by the schematic pictures in Figure $17 a$ and $b$ similar K-values go together with dissimilar plastic wake. fields due to different $d K / d a-v a l u e s$. Apparently it did not upset the $d a / d N-\Delta K$ correlation.

A dK/da-effect was previously suggested [76] to explain crack growth data of flight-simulation tests. It was stated that the similarity approach requires a similar K-cycle, and in addition a similar dK/da in order to obtain similar crack growth rates. Recently the dK/da-effect in flight-simulation tests has been studied by sunder [77], who also found a significant dK/da-effect. He observed dissimilar $S_{o p}$-values for $K$-histories with a positive and a negative $\mathrm{dK} / \mathrm{da}$.

Another example of a dK/da-effect is offered by the initial fast growth of a "mechanically" short edge crack at a hole(Fig.17c). As discussed before the amount of plasticity in the wake of the crack is relatively small for this. crack, and a lower $S_{\text {op }}$ will apply. Moreover, it should not be overlooked that the monotonic plastic zone ahead of the crack will try to prop the crack open. If that zone is relatively large compared to the plasticity in the wake of the crack a lower $S_{\text {op }}$ should be expected.

A rapidly increasing $K$-value (high dK/da) also occurs in a CT specimen (Fig.18d). Tests of Paris and Hermann [68]: on this type of specimen of 2024-T3 material indicated an initial $K_{o p} / K_{\max }=0.5$ which significantly dropped to about 0.2 after $a / W$ exceeding 0.5 . Whether this should be associated with a $\mathrm{dK} / \mathrm{da-effect}$ is uncertain.

The transition from plane strain to plane stress conditions is another complication of the development of the plastic wake field. The wake field will depend on the $K_{\max }$-history, and also on the state of stress and the yield limit of the material. This problem is of great concern to ratigue crack growth models for VA-loading, such as proposed by Dill and Saff [78]. Newman 
[79], Fuehring [80] Dekoning [81] and Baudin and Robert [82]. The more characteristic features of the models are related to predicting changes of $S_{\text {op }}$ during VA-loading, and to the correlation of crack growth rates to those observed under $C A-l o a d i n g$ at similar $\Delta K_{\text {eff }}$-values. It requires that $S_{\text {op }}$ can be predicted both for $V A$ and for CA-loading. Newman [79] made calculations for a CCT specimen. The state of stress (constraint factor $\alpha$ ) apparently had a large effect on $S_{\text {op }}$. The effect of the load level $\left(S_{\max } / S_{y i e l d}\right)$ was moderate, especially so for positive R-ratios. It increased for higher $S_{\max }$-values [79]. In [83]. Newman found $\alpha=1.8$ to give a good fit to crack growth data of 2024-T3 $(t=2.3 \mathrm{~mm}$ ) covering $\mathrm{R}$-values from -1 to 0.7 . For a low alloy steel (HT80, $t=10 \mathrm{~mm}$ ) [21] $\alpha=3$ (plane strain) gave a good $\mathrm{fit}$ in the Paris regime, but surprisingly enough, in the threshold regime $\alpha=1$ (plane stress) gave the better correlation.

Because thin thicknesses will promote the state of plane stress $(\alpha=1)$ a systematic effect of the thickness on $S_{o p}$ and on fatigue crack growth should be expected. Such a trend was reported in the literature, but the effect in most cases is fairly small, and sometimes it is absent or unsystematic. Moreover, shear lips may also contribute to the thickness effect, independently of $S_{o p}$. Newman in [83].says that we do not know the thickness constraint effect very well. and $\alpha$ should therefore be used as a fitting parameter.

Besides all the complicating aspects there is also a reassuring observation. Several investigations on crack closure were carried out on crack growth in different environments, varying from inert to highly aggressive. The results indicate similar crack closure stress levels, irrespective of the environment. This was found for Al-alloys, mild steel and $T i-6-4[28,70,72,84,85]$. In these investigations plasticity induced crack closure was the prevalent closure mechanism. It then should be expected indeed, that monotonic and cyclic plastic zones will develop independently of the environment (exceptions might occur if some constituent of the environment, after diffusing into the material, is changes the yield stress).

\section{CRACK CLOSURE AND VARIABLE-AMPLITUDE LOADING}

Analytical developments

In his second publication Elber [4] already concluded that crack closure does account for retardations (including delayed retardations) and for accelerations, which occur after an overload ( $O L$ ) or a change of the cyclic stress range. He pointed out that crack growth retardation after an $\mathrm{OL}$ is not a consequence of residual compressive stresses ahead of the crack tip, but 
instead it is the result of residual deformations behind the crack tip. Similarly, crack growth accelerations are due to a lack of residual deformations behind the crack tip. These findings have been confirmed in several other investigations later on. It highly stimulated the development of new crack growth models for VA-loading. At the same time it has reduced the physical credibility of other crack growth models if crack closure was not part of it.

Later it became clear that a simple 2-d model, based on plasticity induced crack closure, should still meet with severe problems:

First, a 2-d model easily provides qualitative explanations for certain trends observed in VA tests. However, when it has to be modelled for a quantitative use in cycle-by-cycle calculations, it is no longer such a simple model. For instance, assumptions for the calculation of monotonic and cyclic plastic zone sizes are required. Secondly microscopical and fractographic information on crack growth under VA-loading is steadily increasing. Further analysis of this information has learned that there are several mechanistic aspects, which should be significant for crack growth under VA-loading, and which still cannot easily be accounted for in a 2-d plasticity induced crack closure model. Relevant aspects, partly discussed before, are listed below:

(1) plane strain/plane stress transitions

(2) shear lips

(3) curved crack fronts (even for through cracks)

(4) crack tip blunting

(5) (cyclic) strain hardening of the material

(6) incompatible crack front orientations [86]. (especially in thin sheet mat'erial)

(7) possible changes of the crack growth mechanism when crack growth rates become very small

(8) contributions to crack closure by other mechanisms than wake field plasticity.

An analytical model which includes all these aspects in a physical realistic way, is definitely beyond our present capabilities. It should be hoped that the crack growth conditions for certain categories of practical problems are.

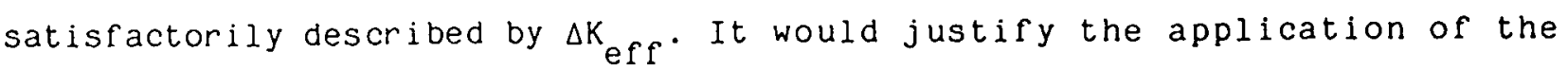
similarity approach, which implies: The relevant $\Delta K_{\text {eff }}$ in an individual load cycle of a VA-load history will produce the same crack extension as the same $\Delta K_{\text {eff }}$ in a $C A$ test. The essential question is whether $\Delta K_{\text {eff }}$ can be the representative field parameter for the effective load increment in a cycle. The previous discussion on mechanistic aspects and measurements problems has made it clear that $3-d$ aspects offer a problem with respect to the definition of 
$S_{\text {op }}$. During unloading the first contacts between the two fracture surfaces of the crack will probably start at the material surface. It implies that the crack tip is closed along a small part of the crack front, which will increase during further unloading, see Figure 18. Such observations were made in transparant materials $[54,55]$. The stress intensity at the open part of the crack front will change, not only because of a change of the load, but also because of a varying amount of the crack closure area. A similar process will occur during uploading. Consequently, it should be expected that $S_{o p}$ and $\Delta K_{\text {eff }}$ will vary along the crack front in some unknown manner, and the definition of a "nominal" $S_{o p}$ is problematic.

Although the 3-d considerations suggest a variation of $\Delta K_{e f f}$ along the,crack front, there are some other arguments why the variations may be smaller than expected. As discussed before the difference between plane strain and plane stress at the interior and the material surface respectively will be reduced by the continuity of the material. Both states of stress cannot develop independently. Secondly, a variation of $\Delta K_{\text {eff }}$ along the crack front will affect the curvature of the crack front, due to faster growth where $\Delta k_{\text {eff }}$ has its maximum. It implies a change of the crack front geometry, which will level out the $\Delta \mathrm{K}_{\text {eff }}$-variation. It should not be overlooked that a parallel shift of the crack front (see the dotted lines in Figure 18. implies a constant crack growth rate along the crack front. In contrast to a previous argument it suggests a constant $\Delta K_{\text {eff }}$ along the crack front (assuming a constant crack growth resistance along the crack front). For practical reasons it appears advisable to measure $S_{o p}$-values not at the material surface close to the crack tip, but at some remote distance. That might yield an $S_{\text {op }}$ with a more "nominal" character, although it will be lacking a firmly based definition.

The second argument (leveling out of $\Delta \mathrm{K}_{\text {eff }}$ along the crack front) will be more applicable to CA-loading than to VA-loading. For VA-loading occasional high loads can modify the shape of the crack front considerably, e.g. by tongue forming (tunneling) for a through crack in a thick plate. For surface cracks the trailing effects mentioned earlier (Fig.4) are another example. More crack closure at the material surface may also contribute to this phenomenon.

Keeping in mind the above complications the question is whether prediction models for VA-loading should recognize different $S_{\text {op }}$-values along the crack front. If it could be done it might lead to more accurate predictions. However, the analytical complications will be large. The present-day models are essentially 2-d models. Both Newman [79] and De Koning [87] have adopted the Dugdale strip yield model for calculating the crack tip plasticity, including the plastic deformations remaining in the wake of the crack. The 
question of plane strain/plane stress is accounted for by the plastic constraint factor $\alpha$. Experience on the applicability and possible restrictions of predictions by these models is gradually building up. Until now it is largely restricted to some aircraft Al-alloys. Apparently there is still much work to do.

Constant $S_{0 p}$ in a stationary VA-test

A cycle-by-cycle calculation requires large computational efforts, depending on the refinements of the prediction model. A much simpler prediction is possible if it could be assumed that $S_{\text {op }}$ during a stationary VA-loading remains constant. Elber [88] observed that $S_{\text {op }}$ in pure random load tests stayed at an approximately constant stress level, which he adopted for the predictions. For stationary flight-simulations tests [67] the present author assumed that $S_{o p}$ in such tests could also be approximately constant. In addition it was assumed that $S_{o p}$ might be deduced from the maximum and the minimum stress occurring in the flight-simulation test in the same way as it was applicable to the CA-tests. The predictions were in reasonable agreement with the, test results, but later experience showed that a significant $\mathrm{dK} / \mathrm{da}$-effect prevented a good agreement for another test series [89].

\section{Practical problems}

The input data for practical prediction problems are schematically indicated in Figure 19. For the discussion here it is assumed that the load spectrum is available from past experience, mission analysis, calculations or measurements. From the external loads on the structure, the stress distribution inside the structure can be calculated. If cracks are present stress intensity factors can also be calculated. The facilities to make this kind of calculations are still improving, but already now an impressive state of the art has been reached.

The material imput data are the crack growth results obtained in the laboratory on simple specimens, preferably covering the complete relevant range of $\Delta K$ and $R$-values. The crux of the problem is the prediction model.

Several aspects are important for predictions in practice, such as the reliability of the predictions and practical consequences of the predicted results with respect to economy and safety of the product. These issues will not be discussed here. However, it should be pointed out that the quality of crack growth predictions will depend on the type of load spectrum and the load sequence occurring in service load-time histories. Some typical load spectrum 
shapes are shown in Figure 20. Load spectrum I could apply to a welded pressure vessel with little variation of the load amplitude. This appears to be the most simple problem; for which fracture mechanics should offer a reasonable solution. Of course there still may be uncertainties associated with material scatter, environmental effects, etc., which should be accounted for by suitable safety factors. The other two spectra in Figure 20 imply more serious problems. Spectrum II is a mixture of high and low loads, whereas spectrum III is still more extreme in this respect. It could apply to a ship propeller with a relatively low number of high manoeuvre loads and numerous small cycles directly coupled to the rotation of the propeller [10]. For many dynamically loaded structures the load history is a superposition of deterministic loads (of the manoeuvre type) as a direct result of using the structure, and stochastic loads due to random excitations. A typical aeronautical example is shown in Figure 21 where the deterministic loads consists of the once per flight load profile, while the stochastic loads are caused by gusts and runway roughness.

Many crack growth investigations employing spectrum loading have revealed various interaction effects between large and small load cycles. In a qualitative sense, these effects can be understood by considering crack closure. Several quantitavily good predictions are reported in the literature, but crack growth prediction is not yet a generally solved problem for any material and any load spectrum. A critical issue is the contribution to crack growth of large numbers of small cycles. Depending on slight shifts of $S_{\text {op }}$ the small cycles can be either rather inslgniflcant or very damaging. As indicated above, such a problem can be especially relevant if vibratory stresses are superimposed on larger load cycles of a much lower frequency. Instead of condidering $S_{o p}$ the latter problem can also be discussed in terms of threshold $\Delta K$-values. Whether this is a good approach is a matter of the similarity between the crack growth phenomenon occurring in service and the threshold testing conditions in the laboratory. If micro structurally sensitive crack growth could occur in the laboratory specimen, and it might not occur in service, it apparently is not a good approach. Caution with threshold. $\Delta K-$ values seems to be wise anyhow. Microstructural sensitive crack growth with raising $S_{o p}$-values can affect $\Delta K_{t h}$ test results in an unconservative way. An extrapolation of crack growth results obtained in the Paris regime to the low $\Delta K$ regime should be advised. It can be done as a linear extrapolation in a double-log plot, see the dotted line in Figure 16. 
Usually predicted crack growth results are compared to test results, either in an $\mathrm{a}-\mathrm{N}$ graph or in a da/dN-a graph. The agreement in such graphs should be satisfactory, because otherwise the prediction is poor. However, if a good agreement is obtained it does not necessarily imply that the prediction model is reliable. The above checks are related to macroscopical crack growth data. It does not exclude incorrect predictions on crack length increments of individual cycles. For instance, consider a simple periodic program with a number of small cycles and another number of large cycles in an alternating sequence. If the crack length increment of the small cycles is underestimated, and the increment of the large cycles is overestimated, the possibility exists that positive and negative inaccuracies on the micro level, will cancel on a macro level. This should be checked by fractographic observations on striations in the electron microscope. If the striation pattern does not agree with the predictions, the model cannot be generally correct. For materials which do not show striations, it is possible to reveal such detailed information from macrocrack growth data, but it then requires carefully planned variations of the load histories adopted.

Test programs to obtain fractographic evidence on crack extensions in individual load cycles should be strongly recommended. It will lead to more precise verifications of crack growth prediction models, and only very limited studies have been carried out so far. Even on a macro level growth bands associated with batches of cycles have not much been used for checking crack growth predictions for individual batches of cycles. Also this should be recommended.

\section{Alternative crack growth prediction techniques}

In the present paper we are dealing with the significance of crack closure for fatigue crack growth. The basic idea of recent models is to adopt $\Delta K_{\text {eff }}$ for $V A$ prediction purposes. However, in the literature other approaches were proposed for the same problem, especially for aeronautical fatigue. In several models loád interaction effects are allowed for by considering plastic zone sizes and by using constants for matching the results of test programs with a variety of load histories (e.g.[90]). There is still another approach with characteristic $K$-values as the basic idea. If a VA-load history has a stationery character the stress level can be defined by some characteristic stress level ( $s_{\text {char }}$ ), for instance the root-mean-square value $\left(S_{r m s}\right)$ for random loading, or the mean stress in flight $\left(S_{m f}\right)$ for a flight-simulation test. A characteristic $K$-value is then obtained as $K_{\text {char }}=C S_{\text {char }} \checkmark / l a$. A unique correlation between the 
growth rate and $K_{\text {char }}$ can then be adopted for prediction purposes. Positive and negative experiences have recently been summarized as part of a survey on flight simulation test data [91]. A limitation of the $K$ char approach should be pointed out here. It requires fatigue test results for any relevant load spectrum to obtain the $d a / d N=f\left(K_{\text {char }}\right)$ function.. Contrary to crack closure based prediction models, it does not allow extrapolations to other load spectra. In other words, for general applications the potential usefulness of crack closure based prediction models should be better.

\section{SUMMARY AND CONCLUSIONS}

Crack closure considerations and a variety of investigations on the'crack closure phenomenon have broadened our views and considerably improved our understanding of the fatigue crack growth process. At the same time it has learned that the crack growth process can be fairly complex, especially under VA-loading. Moreover the process may vary from one material to another one. Apparently the marriage between fracture mechanisms and fracture mechanics is still problematic, but anyhow it is unavoidable for real progress to be made.

\section{Microcracks}

1. Fatigue crack nucleation occurs only in a few selected grains at the material surface. On a micro level it is the result of cooperating unfavourable conditions, such as size and shape of material defects and grains. other factors are the lattice orientation, elastic anisotropy and a lower restraint on cyclic plasticity. It should be expected that several unfavourable conditions, responsible for the nucleation, will also cause an initial fast growth of the very first microcracks, and thus contribute to the so-called small crack problem. The cracks are "microstructurally short".

2. Essential differences between growth mechanisms of microcracks and macrocracks preclude simple correlations between the growth rates of the two types of cracks. Both crack driving forces and the crack growth resistance are different.

3. The initially fast growth of "mechanically short" cracks, nucleated at a notch root, is a result of delayed crack closure. These cracks are not necessarily microstructurally short.

Macrocracks

4. The 2-d crack closure concept for macrocracks is a simplification of a 3d phenomenon. The plane strain/plane stress transition along the crack front, and for some materials the occurrence of shear lips, contribute to the 3-d problem. There are indications of more crack closure at the surface as compared to the interior of the material. 
5. A plane stress plastic tip zone at the material surface cannot freely develop if a large part of the crack front is still under plane strain conditions. The restraint is due to the continuity of the material. As a result the plastic zone size at the surface will be smaller than it is often suggested.

6. Due to microscopical aspects of the growth of a macrocrack, a perfect mating of the upper and lower surface of a fatigue crack should not be expected. It implies that mechanically crack closure will occur locally at points of maximum mismatch between the two surfaces. For Al-alloys this is confirmed by the large amount of undamaged striations and the rare occurrence of tire tracks.

7. For several reasons microscopical observations of fatigue cracks growth on the specimen outer surface can give misleading information mechanistic aspects of fatigue crack growth at the interior of the material.

8. The crack growth mechanism of a macrocrack may change at very low growth rates. Because the crack driving force is very low a smaller number of slip systems will be activated. Microplasticity will be more sensitive for the microstructure of the material. Then microstructurally sensitive crack growth will lead to a more tortuous crack path with local tendencies to slip band cracking, crack branching and other discontinuities. That will further reduce the crack driving force. Moreover, the increased micro roughness will significantly increase crack closure (roughness induced, rubbing and oxidation), which will further reduce the crack driving force. As a result of these synergistic activities the growth mechanism may well become essentially different from the mechanism occurring at higher growth rates (Paris regime). The differences will be strongly material dependent.

\section{CA-loading}

9. Various methods can be adopted for measuring $S_{\text {op }}$. The mechanical compliance methods appear to be the more reliable ones, but still the accuracy problem should begiven careful attention. A fundamental problem is due to the non-homogenuous closing along the crack front ( 3 -d effect) with probably more closure at the material surface. For practical reasons it seems advisable to avoid measurements close to the crack tip on the material surface.

:10. If some function $U=f(R)\left(U=\Delta K_{\text {eff }} / \Delta K\right)$ leads to a good correlation between $d a / d N$ and $\Delta K$ in $C A$-tests at the different $R$-values, the function $U=$ $q " f(R)$ ( $q$ is an arbitrary constant) leads to an equally good correlation. As a consequence, apparently different $U(R)$ relations can give an equally good $f i t$ to CA-data, and a good correlation does not prove that $S_{o p}$ is wellknown.

11. Analytical solutions for calculating $S_{o p}$ require assumptions on the state of stress. Although significant progress is made,problems of plane strain/plane stres transitions still require further study, also for CA-loading, but especially for VA-loading. 


\section{VA-loading}

12. Physically realistic prediction models for crack growth under VA-loading should include the effect of crack closure. If plasticity induced crack closure is the only mechanism causing interaction effects, the main problem of the model is how to account for $3-d$ aspects, including plane strain/plane stress transitions along the crack front and its development during further crack growth. Depending on the material, its thickness and the type of load spectrum, there are possibilities that other interaction mechanisms will become effective. If the spectrum contains rarely occurring high loads causing significant retardations, the low growth rate may be associated with a change of the crack growth mechanism and roughness induced crack closure due to increased irregularities of the crack surface. This will not easily be included in prediction models. For some materials the occurrence of shear lips and the possibility of incompatible crack front orientations are other significant complications for a prediction model.

13. For a load spectrum with relatively many low-amplitude cycles, the damaging effect of these cycles should not be based on crack growth data obtained in CA-tests in the threshold regime with load shedding procedures. It might lead to unconservative predictions. An extrapolation of crack growth data obtained in the Paris regime should be preferred.

14. There is still ample work to be done on reliable crack growth prediction models for VA-loading. The validity of prediction models should also be checked by comparing predicted crack growth increments with fractographic observations for individual load cycles (striations) and groups of similar cycles (growth bands). 


\section{REFERENCES}

[1] Ewing, J.A. and Humphrey, J.C., Phil. Trans., Vol. A 200, 1903, p. 241.

[2] Paris, P.C. Gomez, M.P. and Anderson, W.E., The Trend in Engineering, Vol. 13, 1961, pp. 9-14.

[3] Elber, W., Engineering Fracture Mechanics, Vol. 2, 1970, pp. 37-45.

[4] Elber, W. in Damage Tolerance in Aircraft Structures, ASTM STP486, American Society for Testing and Materials, 1971, pp. 230-242.

[5] Ritchie, R.O. and Suresh, S., Metallurgical Transactions, Vol. 13A, 1982, pp. 937-940.

[6] Suresh, S. and Ritchie, R.o., Metallurgical Transactions, Vol. 13A, 1982, p.1627.

[7] Endo, K., Komai, K. and Ohnishi, K., Mem. Fac. Eng. Kyoto Univ., Vol. 31, 1969, pp. 25-46.

[8] Schijve, J., Engineering Fracture Mechanics, Vol. 11, 1979, pp. $167-221$.

[9] Schijve, J. in Fatigue Thresholds, Fundamentals and Engineering Applications, Vol. II, PP. 881-908, EMAS, 1982.

[10] Helle, H., An Investigation of Ship Propeller Fatigue, Doctor Thesis, Delft Un. of Technology, 1981.

[11] Morris, W.L., James, M.R. and Zurek, A.K., Scripta Metallurgica, Vol. 19, 1985, pp. 149-153.

[12] Zurek, A.K., James, M.R. and Morris, W.L., Metallurgical Transactions, Vol. 14A, 1983, pp. 1697-1705.

[13] Lankford, J., Fatigue of Engineering Materials and Structures, Vol.5, 1982 , pp. 233-248.

[14] Blom, A.F., Hedlund, A., Zhao, W., Fathalla, A., Weiss, B. and Stickler, R., preprint Symposium on Behaviour of Short Fatigue Cracks, Sheffield, Sep. 1985.

[15] De los Rios, E.R., Tang, Z. and Miller, K.J., Fatigue of Engineering Materials and Structures, Vol. 7, 1984, pp. 97-108.

[16] Brown, C.W., King, J.E. and Hicks, M.A., Metal Science, Vol. 18, 1984, pp. 374-380.

[17] Nisitani, H. and Takao, K-I., Engineering Fracture Mechanics, Vol. 15, 1981, pp. 445-456.

[18] Nisitani, H. in Current Research of Fatigue Cracks. The Japanese Society of Materials Science, MRS Vol. 1, 1985, pp. 1-22.

[19] Lankford, J., Davidson, D.L. and Chan, K.S., Metallurgical Transactions, Vol. 15A, 1984, pp. 1579-1587.

[20] Morris, W.L., Metallurgical Transactions, Vol. 11A, 1980, pp. 1117-1123.

[21] Newman Jr., J.C. in Behaviour of Short Cracks in Airframe Components, AGARD Conference Proceedings No. 328, 1983, paper 6 .

[22] Schijve, J. in Fatigue 84, Vol. II, pp. 751-771, EMAS, 1984.

[23] Ritchie, R.O. and'Suresh, S. in Behaviours of short Cracks in Airframe Components, AGARD Conference Proceedings No. 328, 1983, paper 1.

[24] Liu, H.W. in Proceedings of the Crack Propagation Symposium, Cranfield 1961, Vol. II, p.514.

[25] Dixon, J.R., International Journal of Fracture Mechanics, Vol. 1, 1965, pp. 224-243.

[26] Fedderson, F.E. "Fatigue crack Propagation in D6AC Steel Plate for Several Flight Loading Profiles in Dry Air and JP-4 Fuel Environments", Report AFML-TR-72-20, Wright-Patterson Air Force Base, AFML, 1972.

[27] Vogelesang, L.B. and Schijve, J., Fatigue of Engineering Materials and Structures, Vol. 3, 1980, pp. 85-98.

[28] Schijve, J. and Arkema, W.J., "Crack Closure and the environmental effect on fatigue crack growth", Report VTH-217, Delft Un. of TechnologY, 1976.

[29] Schijve, J.. "Analysis of the Fatigue Phenomenon in Aluminium Alloys", NLR-TR M.2122, National Aerospace Laboratory NLR, Amsterdam, 1964 . 
[30] Lindley, T.C. and Richards, C.E., Materials Science and Engineering, Vol. 14, 1974, pp. 281-293.

[31] Ewalds, H.L. and Furnee, R.T., International Journal of Fracture, Vol. 14, 1978, pp. R53-R55.

[32] MCEvily, A.J., "Current Aspects of Fatigue, Overload Experiments", Fatigue 1977 Conference, Un. of Cambridge.

[33] Bowles, C.Q., "An Experimental Technique for Vacuum Infiltration of Cracks with Plastic and Subsequent Study in the Scanning Electron Microscope", Report LR-249, Delft Un. of Technology, 1977.

[34] Bowles, C.Q. and Schijve, J. in Fatigue Mechanisms: Advances in Quantitative Measurement of Physical Damage, ASTM STP811, American Society of Testing and Materials, 1983, pp. 400-426.

[35] Stubbington, C.A. and Gunn N.J.F., "Effects of Fatigue Crack Front Geometry and Crystallography on the Fracture Toughness of Ti-6Al-4V Alloy", Repoit : TR 77158, Royal Aircraft Establishment, 1977.

[36] Suresh, S., Engineering Fracture Mechanics, Vol. 18, 1983, pp. 577-593.

[37] Lankford, J. and Davidson, D.L. in Advances of Fracture Research (Fracture 81), Vol. 2, pp. 899-906, Perramon 1981.

[38] Lindley, T.C. in Subcritical crack Growth due to Fatigue, stress Corrosion and Creep, Ispra Course 1981, Elsevier 1984, pp. 167-213.

[39] Minakawa, K. and McEvily, A.J. in Fatigue Thresholds, Fundamentals and Engineering Applications, Vol. I, pp. 373-390, EMAS 1982.

[40] Blom, A.F. in Fatigue Crack Growth Threshold Concepts, American Institute of Mining, Metallurgical and Petroleum Engineers, 1984.

[41] Donehoo, P. Yu, W. and Ritchie, R.O., Material Science and Engineering, Vol. 74, 1985, pp. 11-17.

[42] Ritchie, R.O., Zaiken, E. and Blom, A.F. in Fundamental Questions and Critical Experiments on Fatigue, ASTM Workshop/Symposium, October 1984 .

[43] Bailon, J.P., Chappins, P., Massounave, J. and Dickson, J.I. in Fatigue Thresholds, Fundamentals and Engineering Applications, Vol. I, pp.277-291.

[44] Robin, C. and Pluvinage, G., Fatigue of Engineering Materials and structures, Vol. 3, 1980, pp. 147-157.

[45] James, M.N. and Knott, J.F., Fatigue and Fracture of Engineering Materals and Structures, Vol. 8, 1985, pp. 177-191.

[46] Staal, H.U. and Elen, J.D., Engineering Fracture Mechanics, Vol. 11, 1979, pp. 275-283.

[47] Davidson, D.L. and Nagy, A., Journal of Physics E, Scientific Instruments, Vol. 11, 1978, pp. 207-210.

[48] Nisitani, H. and Kagi, M., in Fracture 1979 (ICF4), Vol. 2, pp.1099-1108, Un. of Waterloo Press.

[49] Shin, C.S. and Smith, R.A., International Journal of Fatigue, Vol. 7, 1985, pp. 87-93.

[50] Williams, D.R., Davidson, D.L. and Lankford, J.,Experimental Mechanics, Vol. 20, 1984, pp. 134-139.

[51] Sharpe, W.N. and Grandt, A.F. in Mechanics of Crack Growth, ASTM STP 590, American Society for Testing and Materials, 1976, pp. 302-330.

[52] Marci, G. and Packman, P.F., Materialprüfung, Vol. 18, 1976, pp.260-265.

[53] Nowack, H., Trautmann, K.H., Schulte, K. and Lütgjering, G. in Fracture Mechanics, ASTM STP677, American Society for Testing and Materials, 1979, Pp. 36-53.

[54] Packman, P.F. in Experimental Techniques in Fracture Mechanics, Vol. 2, Society of Experimental Stress Analysis, 1975, pp. 59-87.

[55] Ray, S.R. and Andrew, S.P., American Institute of Aeronau.tics and Astronautics, paper AIAA-85-0161, 1985.

[56] Beevers, C.J. (Ed.), Advances in Crack Length Measurement, EMAS, 1982. 
[57] Baik, J.M., Hermann, L. and Arsoro, R.J. in Mechanics of Fatigue, AMD-Vol. 47, American Society of Mechanical Engineering, 1981, pp.33-51.

[58] Fleck, N.A. and Smith, R.A., International Journal of Fatigue, Vol. 4, 1982, pp. 157-160.

[59] Fleck, N.A., "An Investigation on Fatigue Crack Closure", Dissertation Cambridge Un., Nov. 1983.

[60] Bachmann, V. and Munz, D., Journal of Testing and Evaluation, vol. 4, 1976, pp. 257-260.

[61] Lal, K.M., Garg, S.B.I. and LeMay, I., Journal of Engineering Materials and Technology, Vol. 102, 1980, pp. 147-152.

[62] Ho, C.L., Buck, O. and Marcus, H.L., in Progress in Flaw Growth and Fracture Toughness Testing, ASTM STP 536, American Society of Testing and Materials, 1973, pp. 5-21.

[63] De Koning, A.U., "A Study of Cyclic Crack Tip Plasticity and Crack Closure Under Variable-Amplitude Loading", NLR TR 81141 L, National Aerospace Laboratory NLR, Amsterdam 1981.

[64] Pelloux, R.M., Faral, M. and McGee, W.M., in Fracture Mechanics, ASTM STP 700, American Society for Testing and Materials, 1980, pp.35-48.

[65] Sunder, R. and Dash, P.K., International Journal of Fatigue, Vol. 4, 1982, pp. 97-105.

[66] Zhang, C., Marissen, R., Schulte, K., Trautmann, K.H., Nowack, H. and Schijve, J., "Crack Propagation Studies on Al 7475 on the Basis of Constant Amplitude and Selective Variable Amplitude Loading Histories, 1985 (to be published).

[67] Schijve, J., in Fracture Mechanics, ASTM STP 700, American Society for Testing and Materials, 1980, pp. 3-34.

[68] Paris, P.C. and Hermann, L. in Fatigue Thresholds, Fundamentals and Engineering Applications, Vol. I, pp. 11-32, EMAS 1982.

[69] Katcher, M. and Kaplan, M., in Fracture Toughness and Slow-Stable Cracking, ASTM STP 559, American Society for Testing and Materials, 1974, pp. 264-282.

[70] Clerivet, A. and Bathias, C., Engineexing Fracture Mechanics, Vol. 12, 1979, pp. 599-611.

[71] Schijve, J., Engineering Fracture Mechanics, Vol. 14, 1981, pp. 461-465.

[72] Dilling, D., "Some Aspects of the Crack Growth Behaviour of Steel Plate Fe 52 Under Variable-Amplitude Loading" (in Dutch), Report 6-78-2, Stevin Laboratory, Delft Un. of Technology, 1979.

[73] Kurihara, M., Kato, A. and Kawahara, M., in Current Research of Fatigue Cracks. The Japanese Society of Materials Science, MRS Vol, 1, 1985, pp. 217-233.

[74] Donaldson, D.R. and Anderson, W.E. in Proceedings of the Crack Propagation Symposium, Cranfield 1961, Vol.II, pp. 375-441.

[75] Figge, I.E. and Newman, J.C. in Fatigue Crack Propagation, ASTM STP 415, American Society for Testing and Materials, 1967, pp. 71-93.

[76] Schijve, J., Jacobs, F.A. and Tromp P.J., "Fatigue Crack Growth in Aluminium Alloy Sheet Material under Flight-Simulation Loading, Effects of Design Stress Level and Loading Frequency", NLR TR 72018, National Aerospace Laboratory NLR, Amsterdam 1972.

[77] Sunder, R. in Fatigue 84, Vol. II, pp. 881-892, EMAS 1984.

[78] Dill, H.D. and Saff, C.R. in Fatigue Crack Growth Under Spectrum Loads, ASTM STP 595, Amexican Society for Testing and Materials, 1976, pp. 306-319.

[79] Newman, J.C. in Methods and Models for Predicting Fatigue Crack Growth Under Random loading, ASTM STP 748, American Society for Testing and Materials, 1981, pp. 53-84.

[80] Führing, $\mathrm{H}$. in Proceedings 2nd Interaction Conference on Numerical Methods in Fracture Mechanics, Swansea, 1980. 
[81] De Koning, A.U. in Fracture Mechanics, ASTM STP 743, American Society for Testing and Materials, 1981, pp. 63-85.

[82] Baudin, G. and Robert, M., in Aircraft Fatigue in the Eighties (11th ICAF Symposium), National Aerospace Laboratory NLR, Amsterdam, 1981, paper 2.7.

[83] Newman, J.C., International Journal of Fracture, Vol. 24, 1984, pp.R131-R135.

[84] Bachmann, V. and Munz, D., International Journal of Fracture, Vol. 11, 1975, pp. 713-716.

[85] Ewalds, H.L., Van Doorn, F.C. and Sloof, W.G., in corrosion Fatigue: Mechanics Metallurgy, Electrochemistry and Engineering. ASTM STP 801, American Society for Testing and Materials, 1983, pp. 115-134.

[86] Schijve, J., Engineering Fracture Mechanics, Vol. 6, 1974, pp.242-252.

[87] De Koning, A.U., "Criteria for the Determination of Significant Load Cycles in Variable-Amplitude Load Sequences", NLR MP 86013, National Aerospace Laboratory NLR, Amsterdam 1986 (to be published).

[88] Elber, W. in Fatigue Crack Growth Under Spectrum-Loading, ASTM STP 595, American Society for Testing and Materials, 1976, pp.236-247.

[89] Schijve, J., "Prediction of Fatigue Crack Growth in 2024-T3 Alclad Sheet Specimens Under Flight-Simulation Loading. Results From A GARTIEUR Progran", Memorandum M-415, Delft Un. of Technology, 1981.

[90] Chang, J.B. and Hudson; C.M. (eds), Methods and Models for. Predicting Fatigue Crack Growth Under Random Loading, STP 748. American Society for Testing and Materials, 1982.

[91] Schijve, J. in Durability and Damage Tolerance in Aircraft Design, Proceeding 13th ICAF Symposium, Pisa 1985, EMAS 1985, pp. 71-170. 
Table 1 Characteristic differences between microcracks and macrocracks [9]

DIFFERENCE BETWEEN THE GROWTH OF

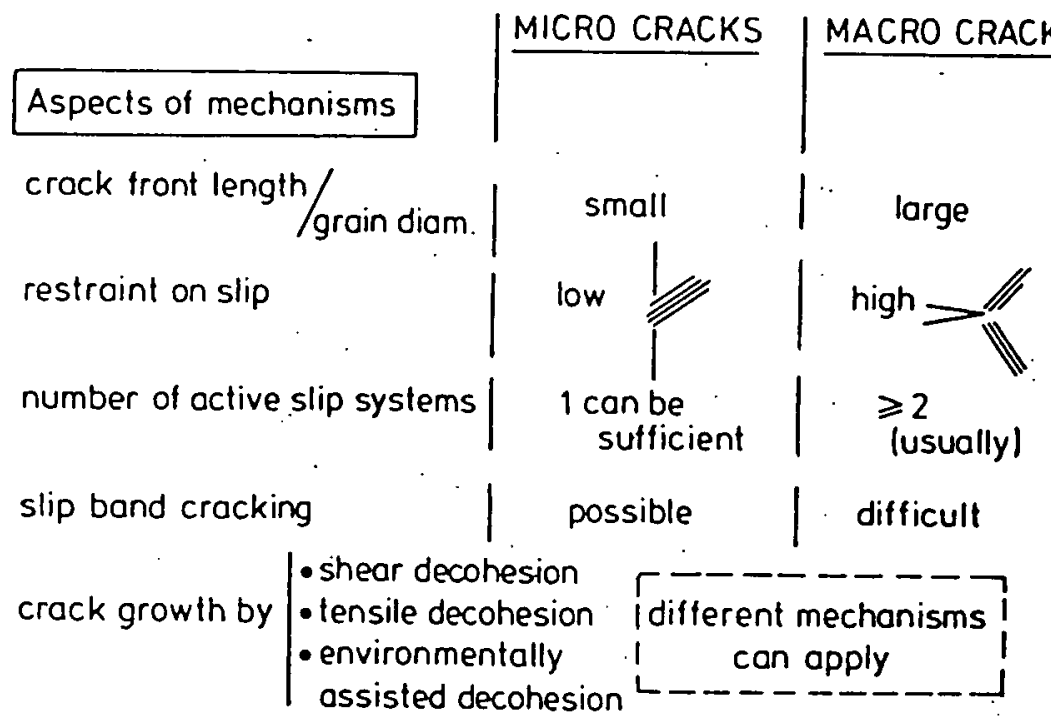

striations

no

yes

plosticity in wake of crack $\mid$ limited $\mid$ evident

fracture surface topogrophy

? $\quad \begin{gathered}\text { not flat on } \\ \text { micro }\end{gathered}$

Aspects of material

inhomogeneity

elastic anisotropy

|can be significant / averaged effect

inclusions

\begin{tabular}{|l|l} 
can start micro & $\begin{array}{c}\text { small effect } \\
\text { (sometimes } \\
\text { cracks }\end{array}$
\end{tabular}

grain boundaries

|can be significant |average effect

- moterial surface examples: large effect / | negligible effect

layer nitriding llocal properties) (bulk properties) decarburizing shot peening

rough surface 
Table 2: Main differences between two types of small cracks [22].

TWO DIFFERENT TYPES OF "Small cracks"

Characteristic

observation

cause

1. Microstructural

discont inuous

microstructural short crack

microcrack grow

inhomogeneities

of the material

2. Mechanically

initial fast growth short crack of small crack

initially high $\Delta S$ due to "delayed" eff crack closure

Table 3: Survey of methods to measure $S_{o p}$ (or $S_{c l}$ ).

Direct observations of crack cosure at the crack tip

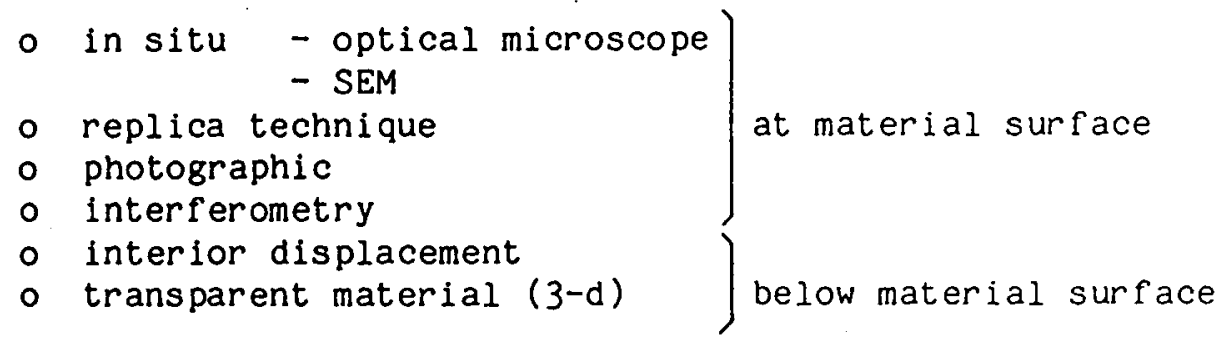

Compliance measurement

- mechanical compliance - clip gages . near crack tip

. remote from crack tip

- strain gages . on crack (COD)

- near crack

- remote from crack tip

- physical compliance - potential drop method

- eddy current

- ultrasonic

Indirect observations based on fatigue crack growth

- (zero) crack growth rate observations during VA-loading

- strlation spacing methods during VA-loading

- calibration by high-R tests, CA-loading 


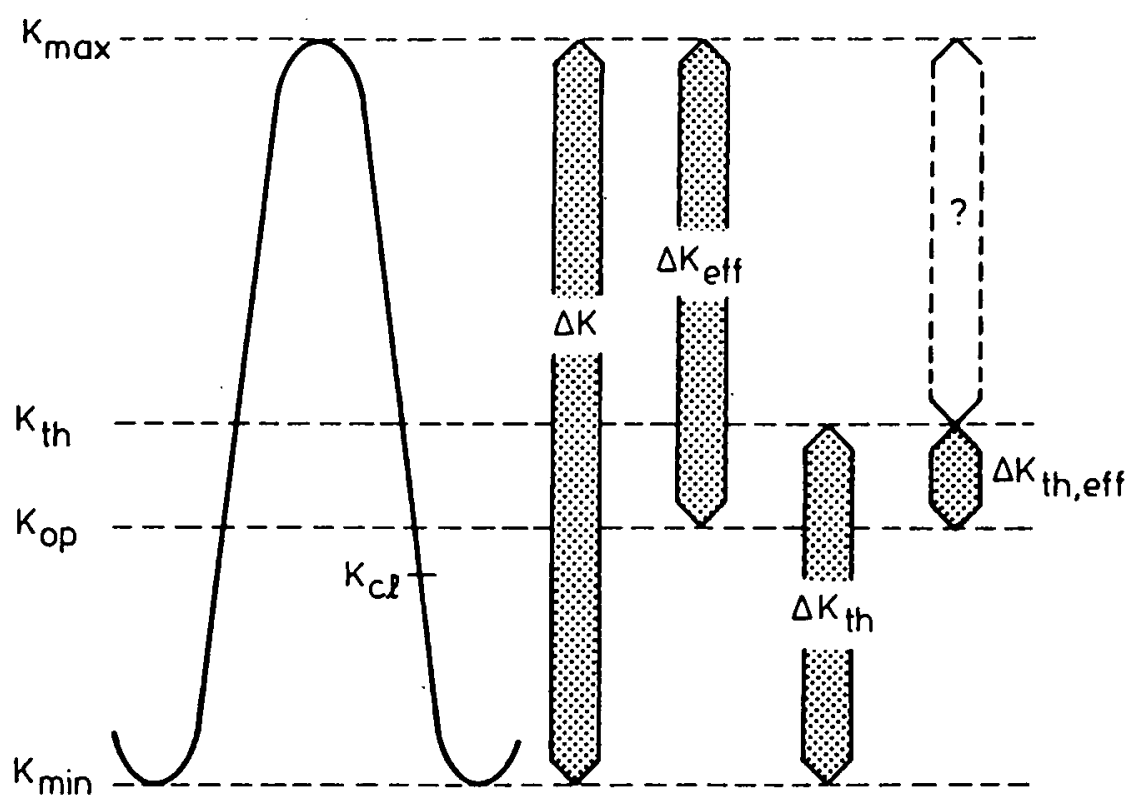

$$
\begin{aligned}
& R=\frac{K_{\text {min }}}{K_{\text {max }}} \\
& U=\frac{\Delta K_{\text {eff }}}{\Delta K} \\
& \gamma=\frac{K_{\text {op }}}{K_{\text {max }}} \\
& U=\frac{1-\gamma}{1-R}
\end{aligned}
$$

Figure 1: Definitions of the various K-values. Similar definitions apply to the stress $s$.

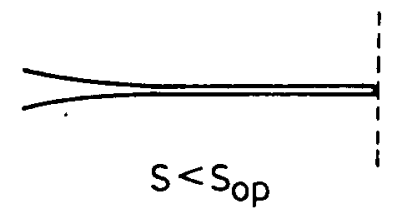

crack partially closed

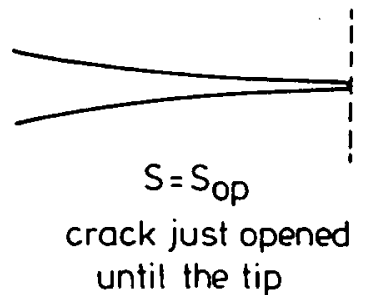

until the tip

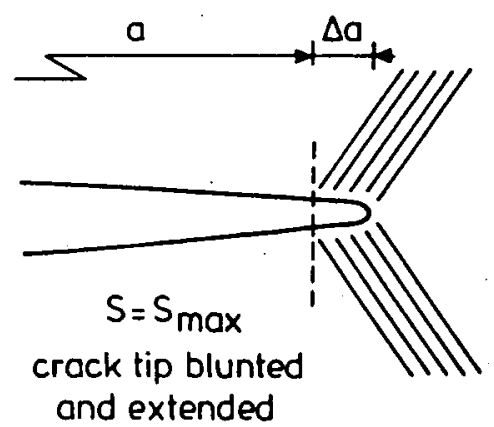

Figure 2: Ideal 2-d crack opening as a smooth unfolding mechanism.

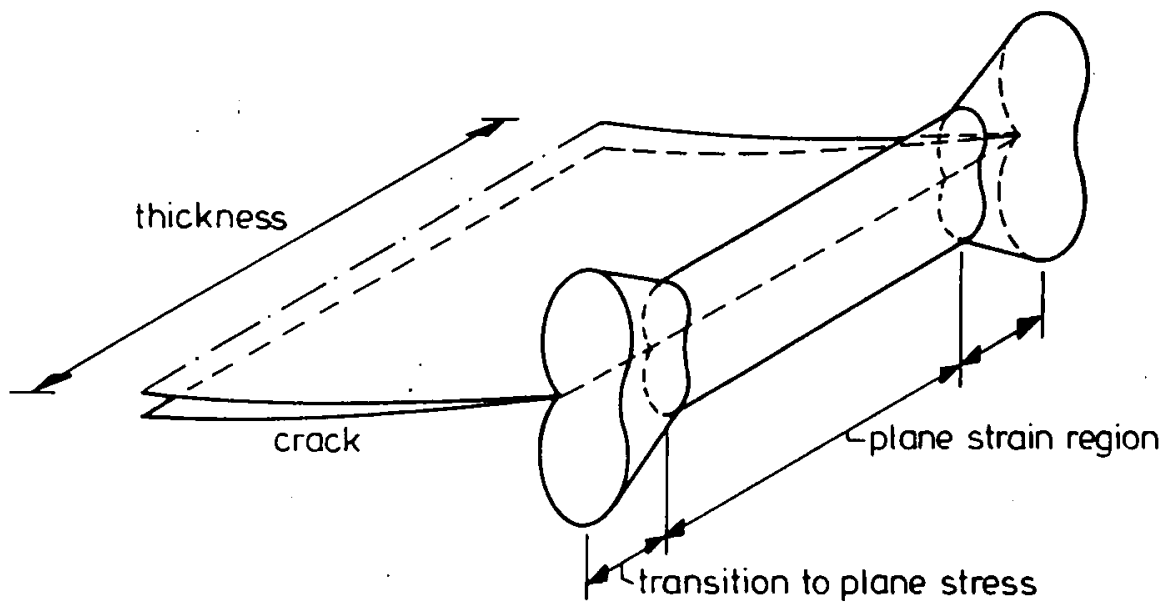

Figure 3: Variation of plastic zone size along the crack front [24, 25]. 


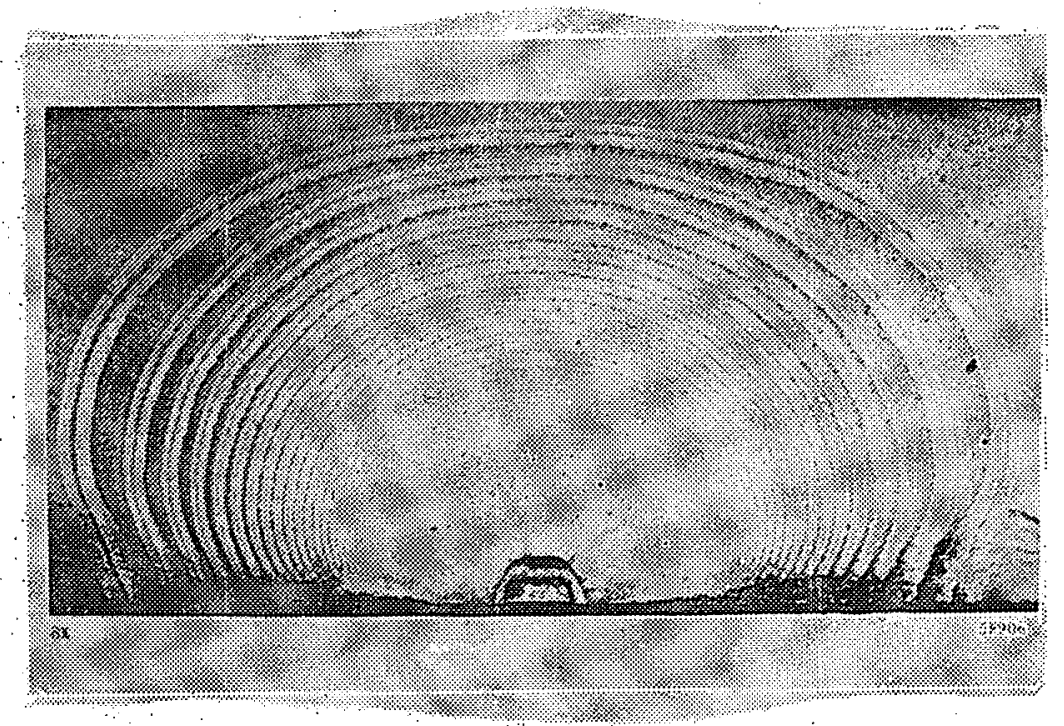

Foure 4: cuved crack rents with traing ends at the material surface, weac stee, $r=15$ ma $[26]$.

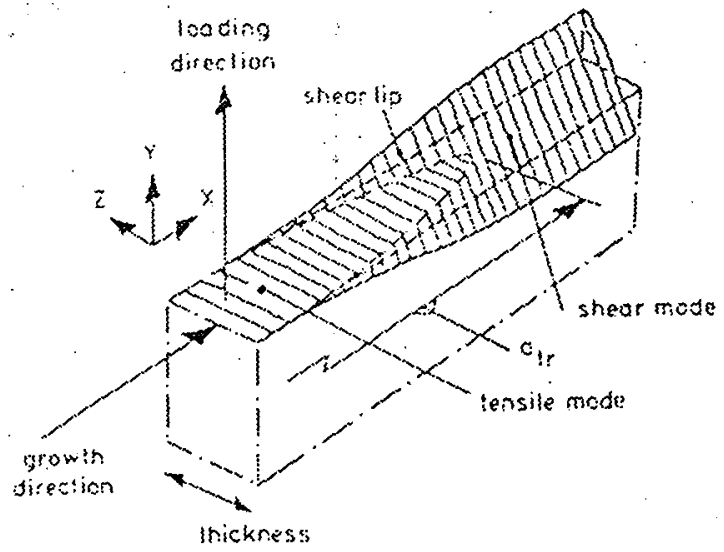

Fique 5: Practure sarace of a fatigue crack in sheet material with atransition from the tensile mode to the shear mode.

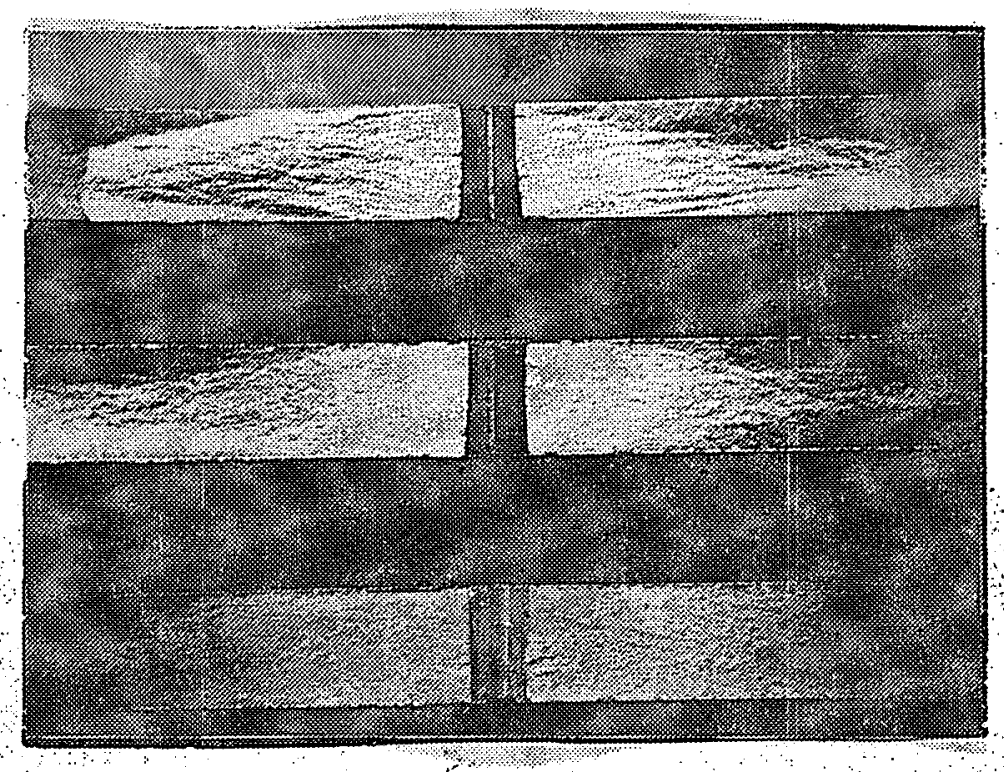

vacuum

air

sall water

Figure 6. Surtace roughness depending on environment. "crack growth in $7075 . \mathrm{re}(6 \mathrm{~mm})[28]$. 


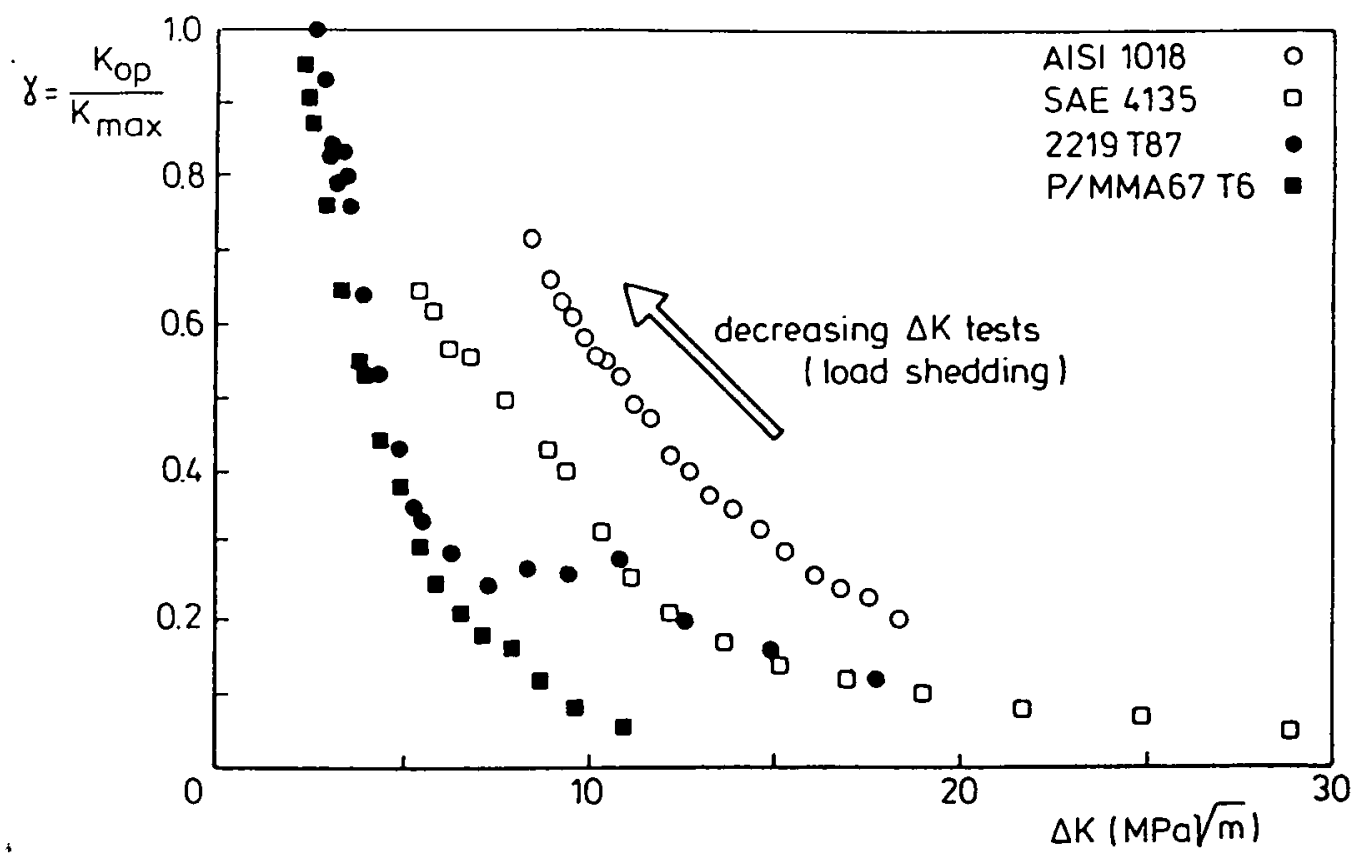

Figure 7: Increasing $K_{o p} / K_{\max }$ during $K_{\text {th }}$-tests $(R=0.05)$. Results of Minakawa and McEvily [39].

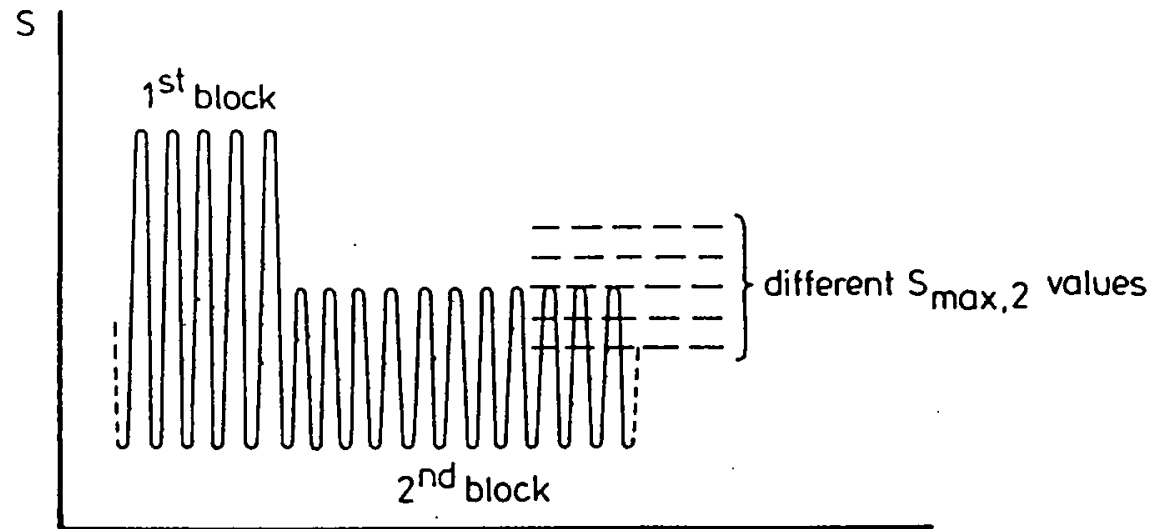

cycles

Figure 8: $\mathrm{S}_{\mathrm{op}}$ in the first block is maximum value of $\mathrm{S}_{\max , 2}$ which does not give further crack growth [63].
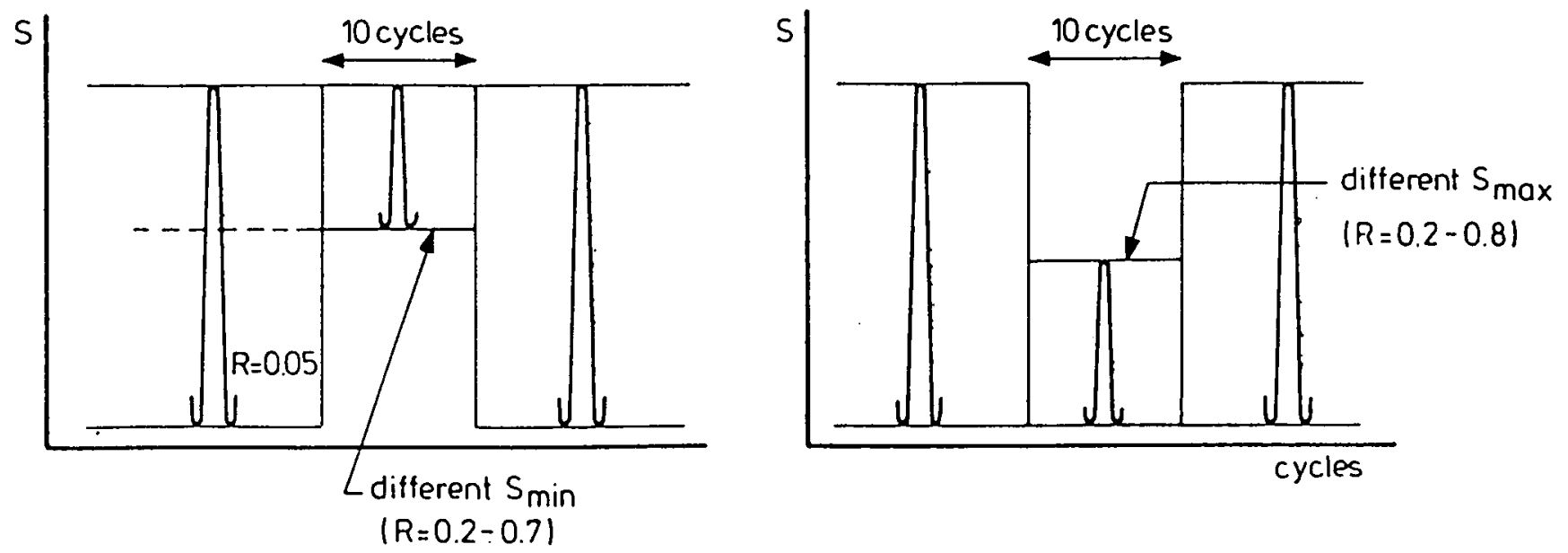

Figure 9: Load sequences applied by Pelloux et al [64] to obtain $S_{\text {op }}$ from striation measurements. 

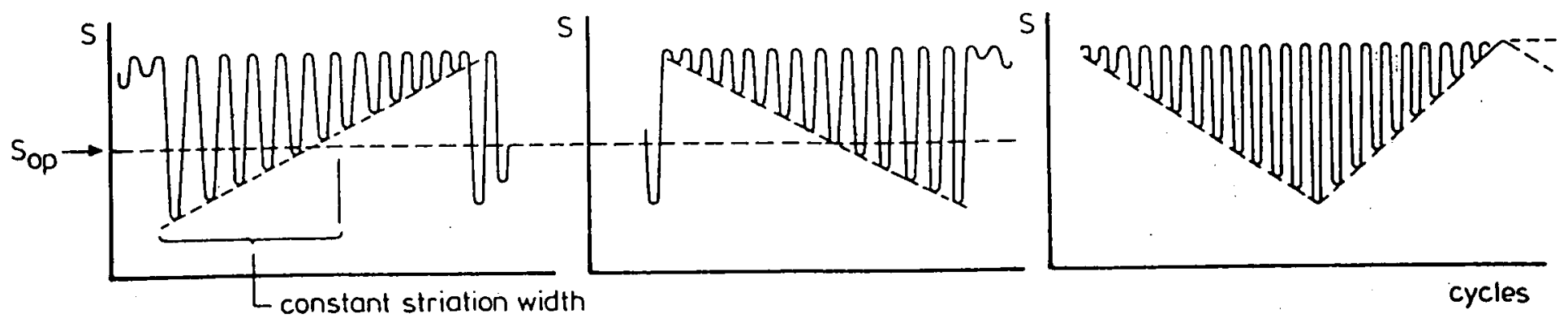

Figure 10: Load sequences adopted by sunder and Dash [65] to obtain sop from striation measurements.

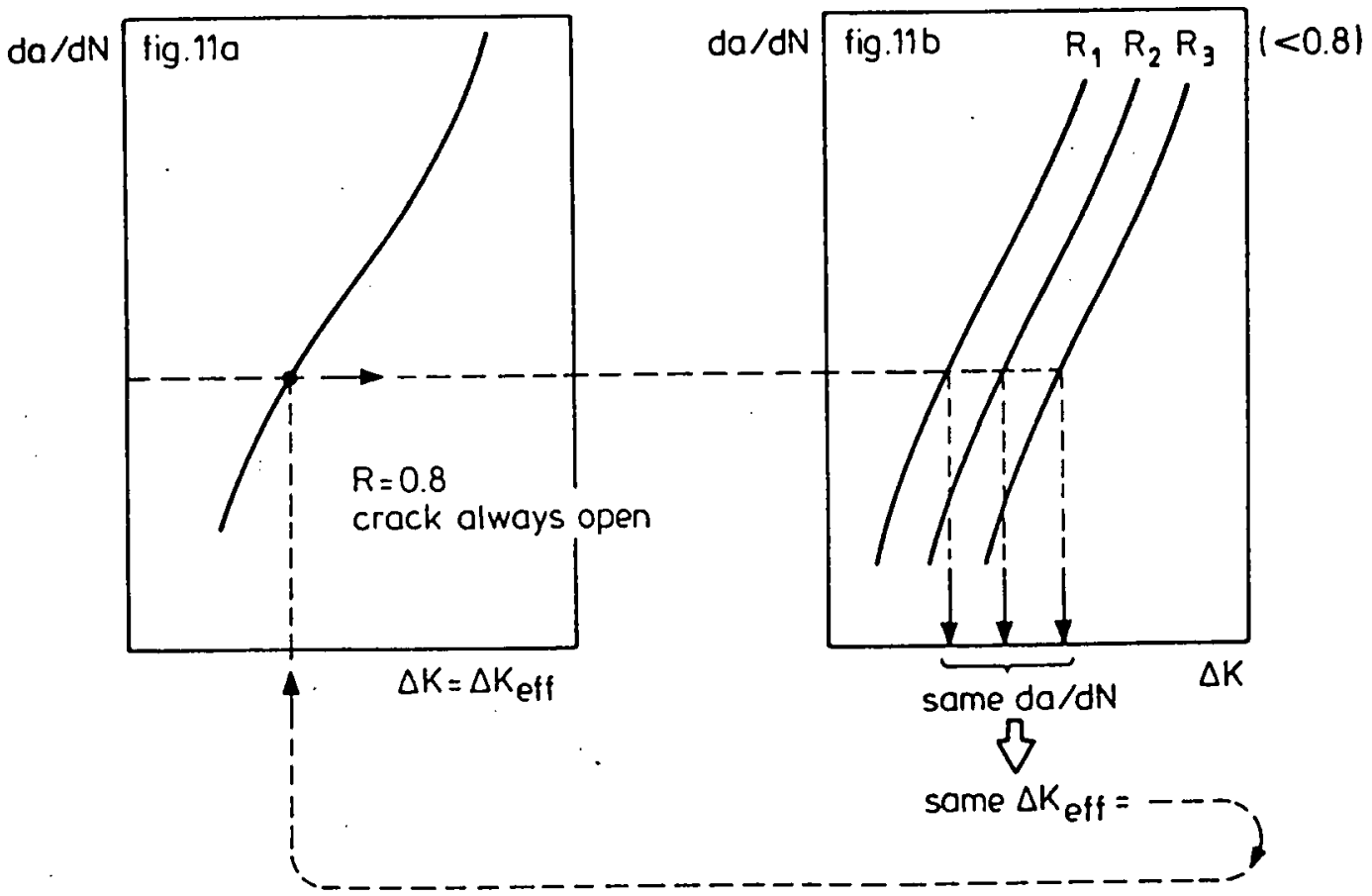

Figure 11: Derivation of $\Delta \mathrm{K}_{\text {eff }}$ from da/dN, method adopted by zhang et al [66]. 


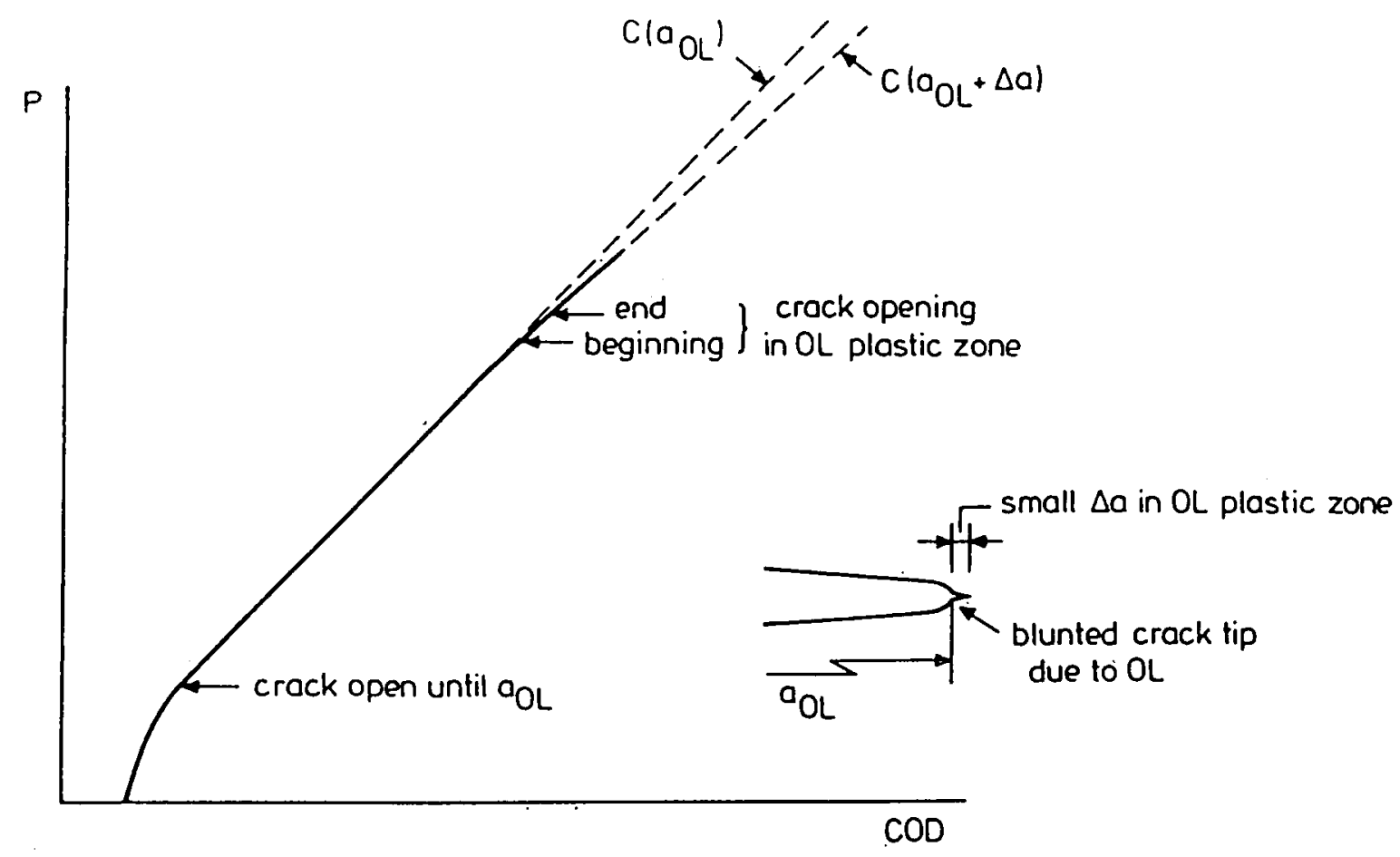

Figure 12: Opening of small crack extension in plastic zone of overload (OL).

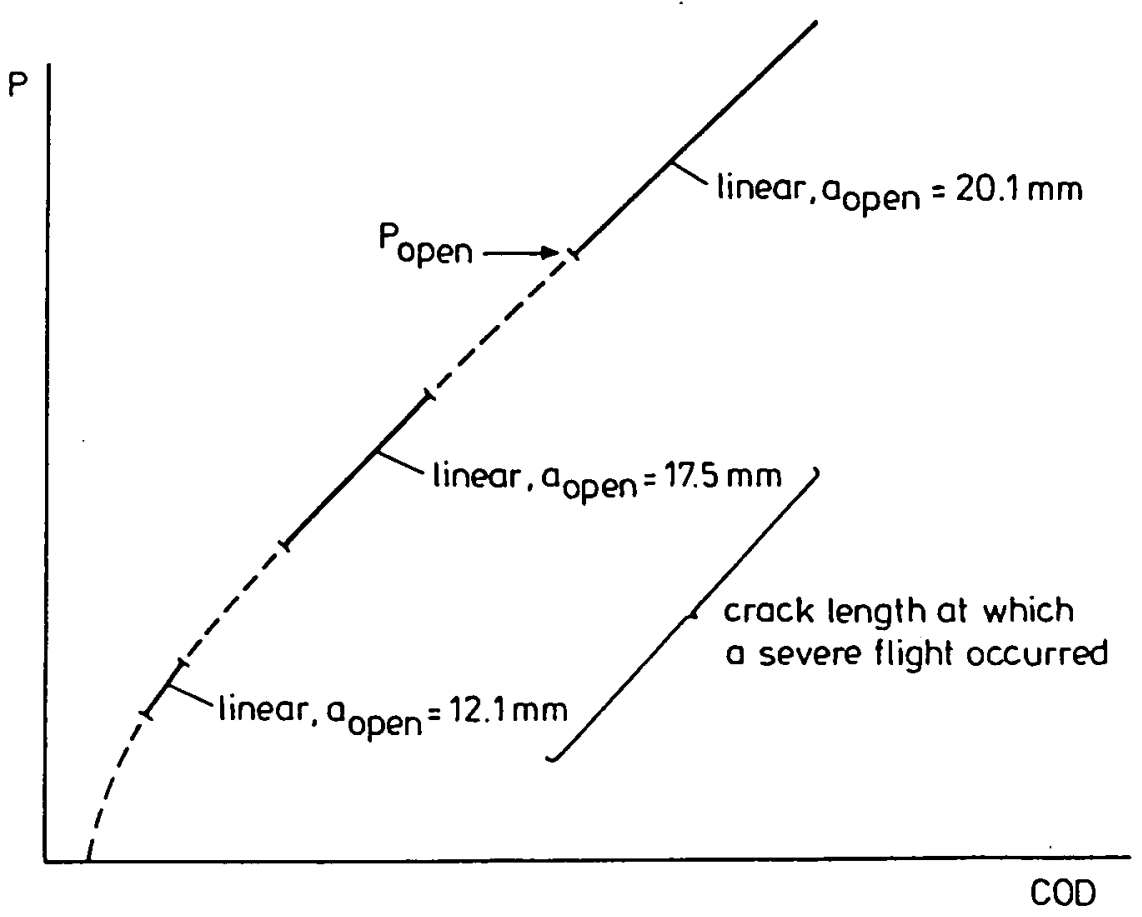

Figure 13: More linear parts in a $P-C O D$ record due to large plastic zones in a flight-simulation fatigue test on a 7075-T6 CCT specimen $(t=2 \mathrm{~mm})[67]$. 


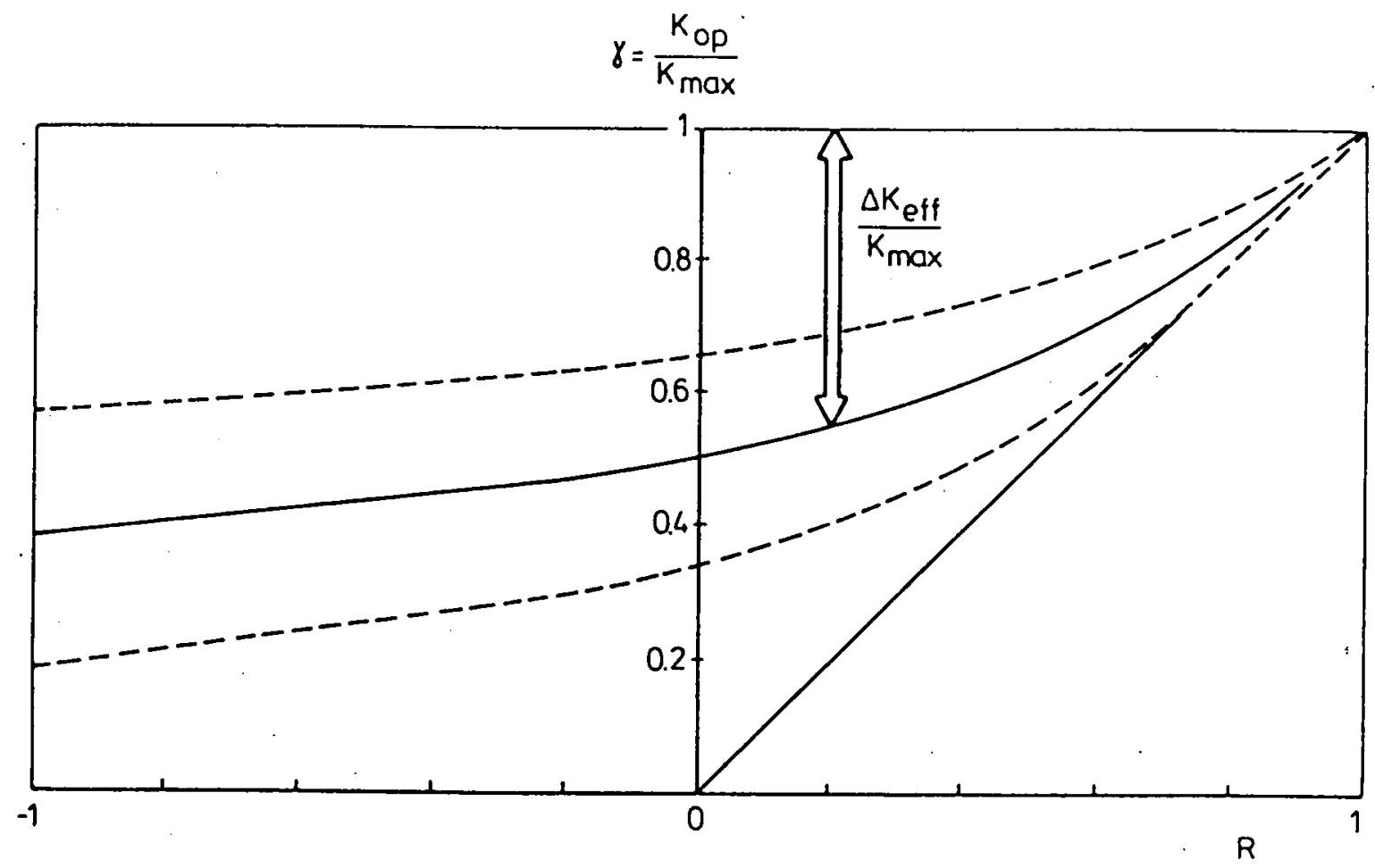

Figure 14: $\mathrm{K}_{\mathrm{Op}}$ and $\Delta \mathrm{K}_{\mathrm{eff}}$ as a function of $\mathrm{R}$, general picture.

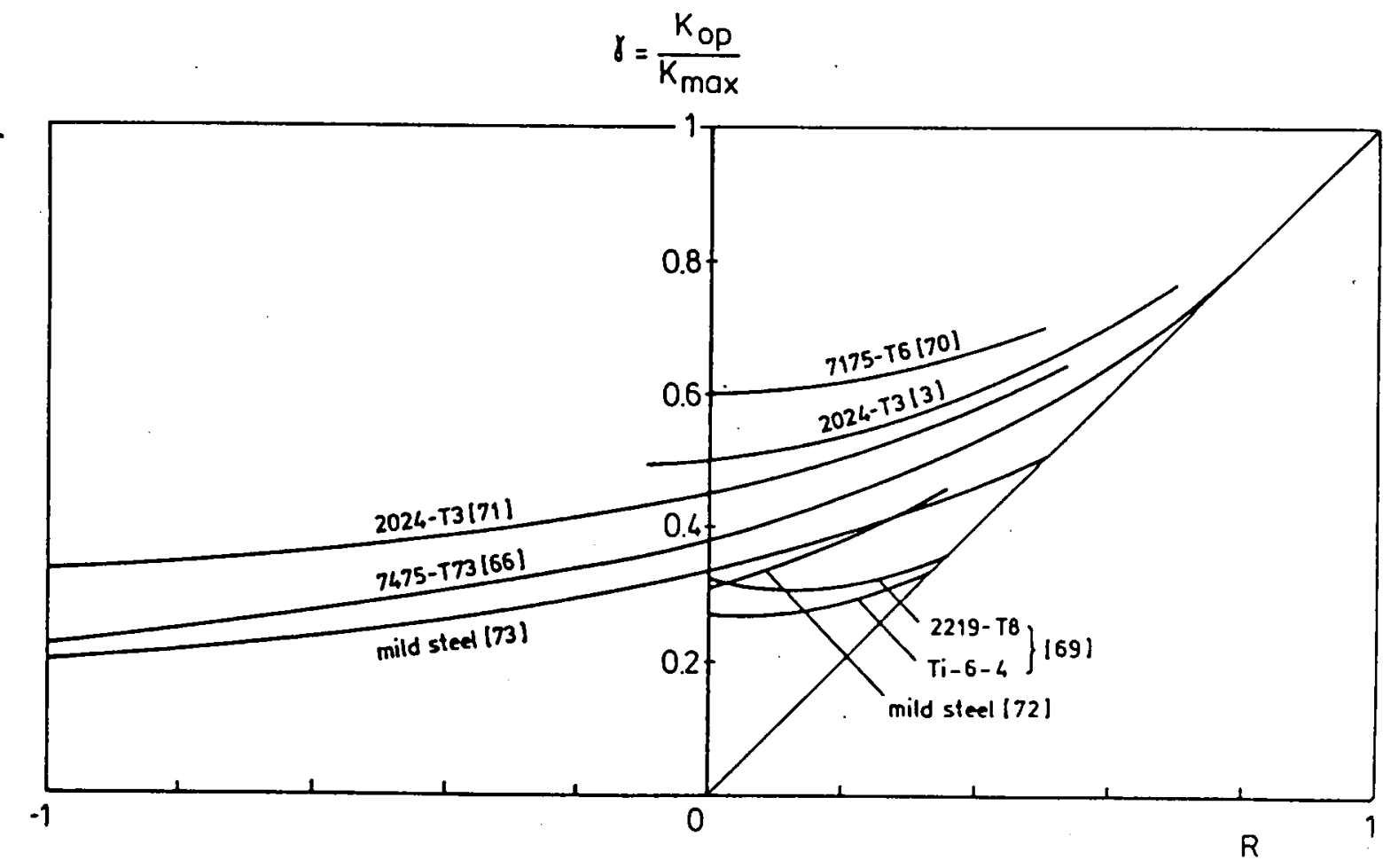

Figure 15: Examples of empirically observed $\mathrm{K}_{\mathrm{op}} / \mathrm{K}_{\max }-\mathrm{R}$ relations. 


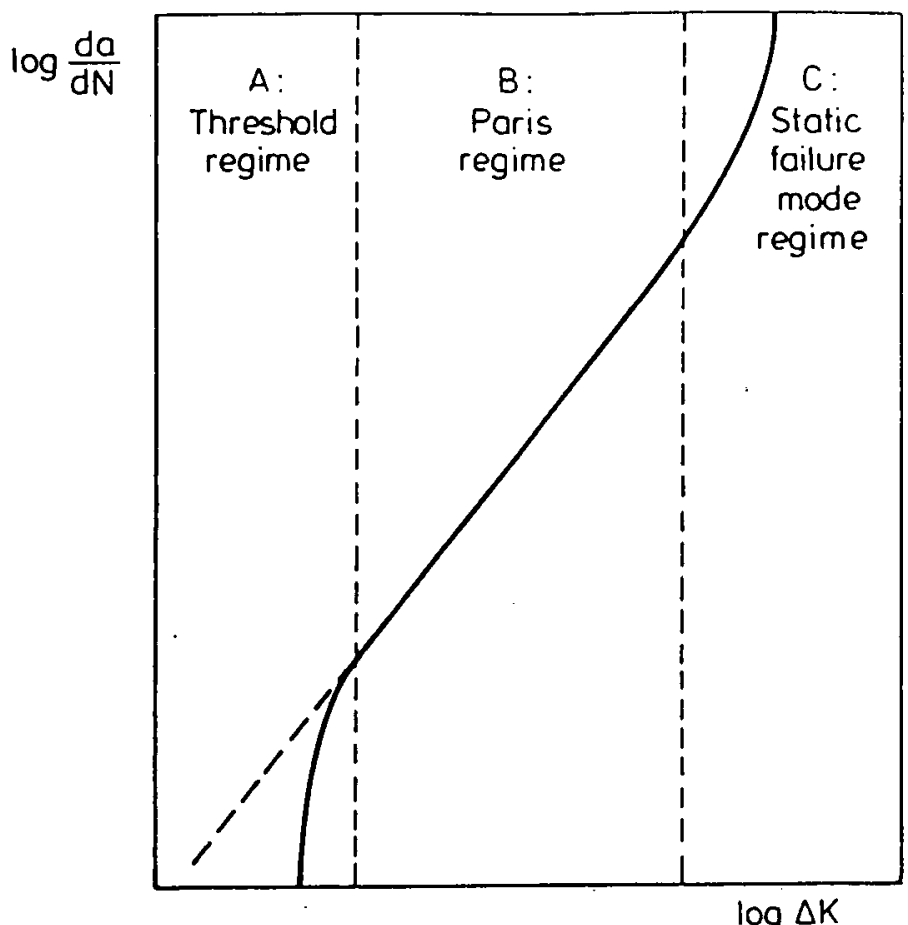

Figure 16: Three regimes of the crack growth rate.

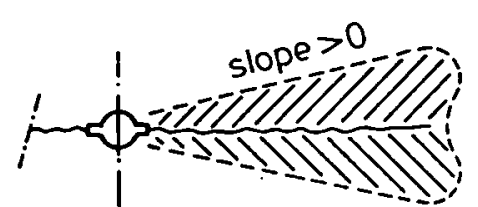

fig.17a: CCT specimen, CA-loading

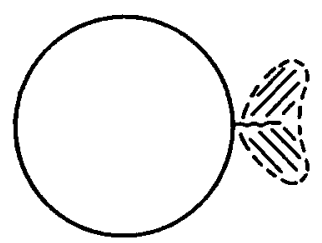

fig. 17c : small hole edge crack

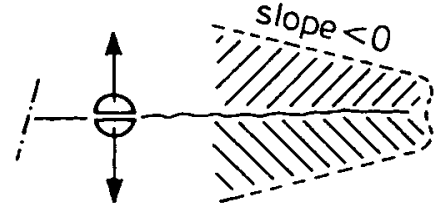

fig. 17b: CCT specimen, crack edge looding

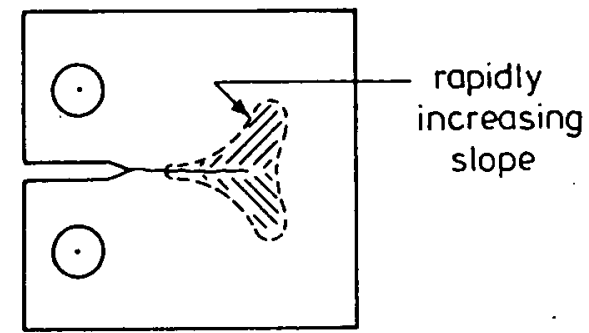

fig. 17d: CCT specimen, CA-loading

Figure 17: Schematic pictures of plastic wake fields.

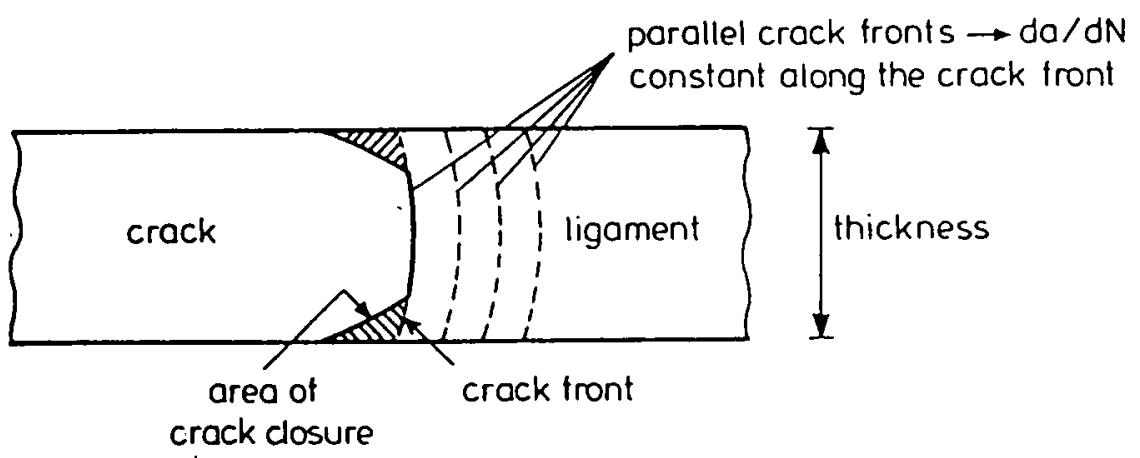

Figure 18: Crack tip partially closed. 


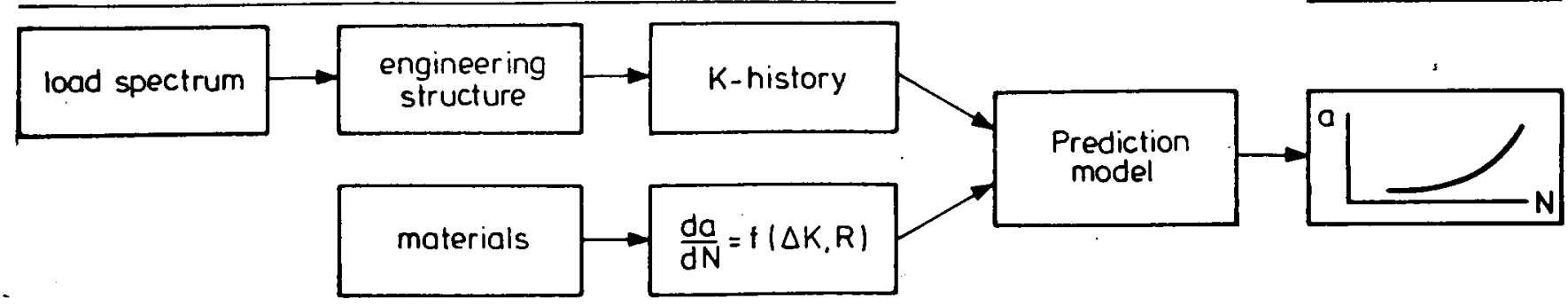

Figure 19: Schematic diagram of the practical fatigue crack growth prediction problem.

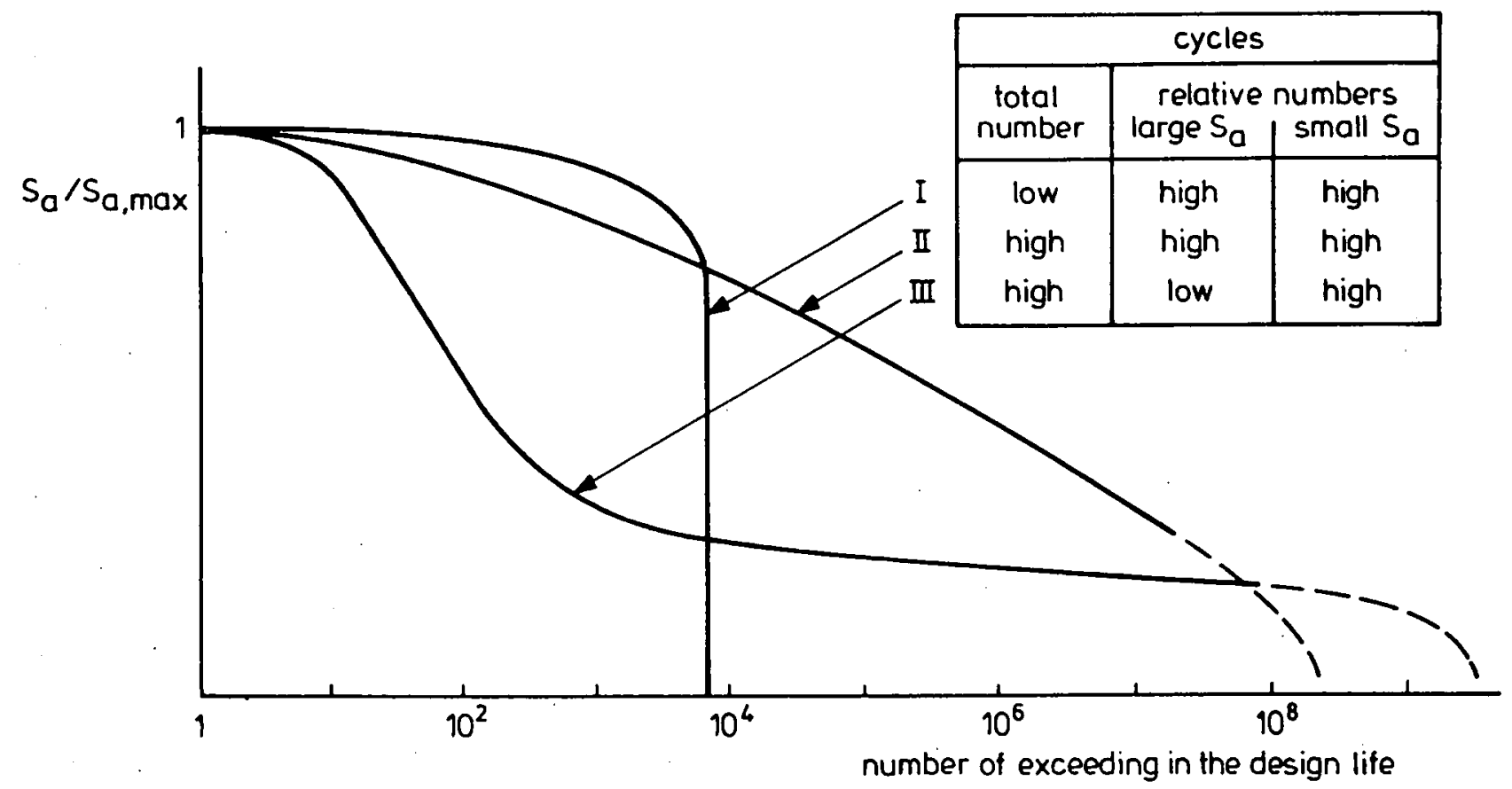

Figure 20: Three different types of load spectra [22].

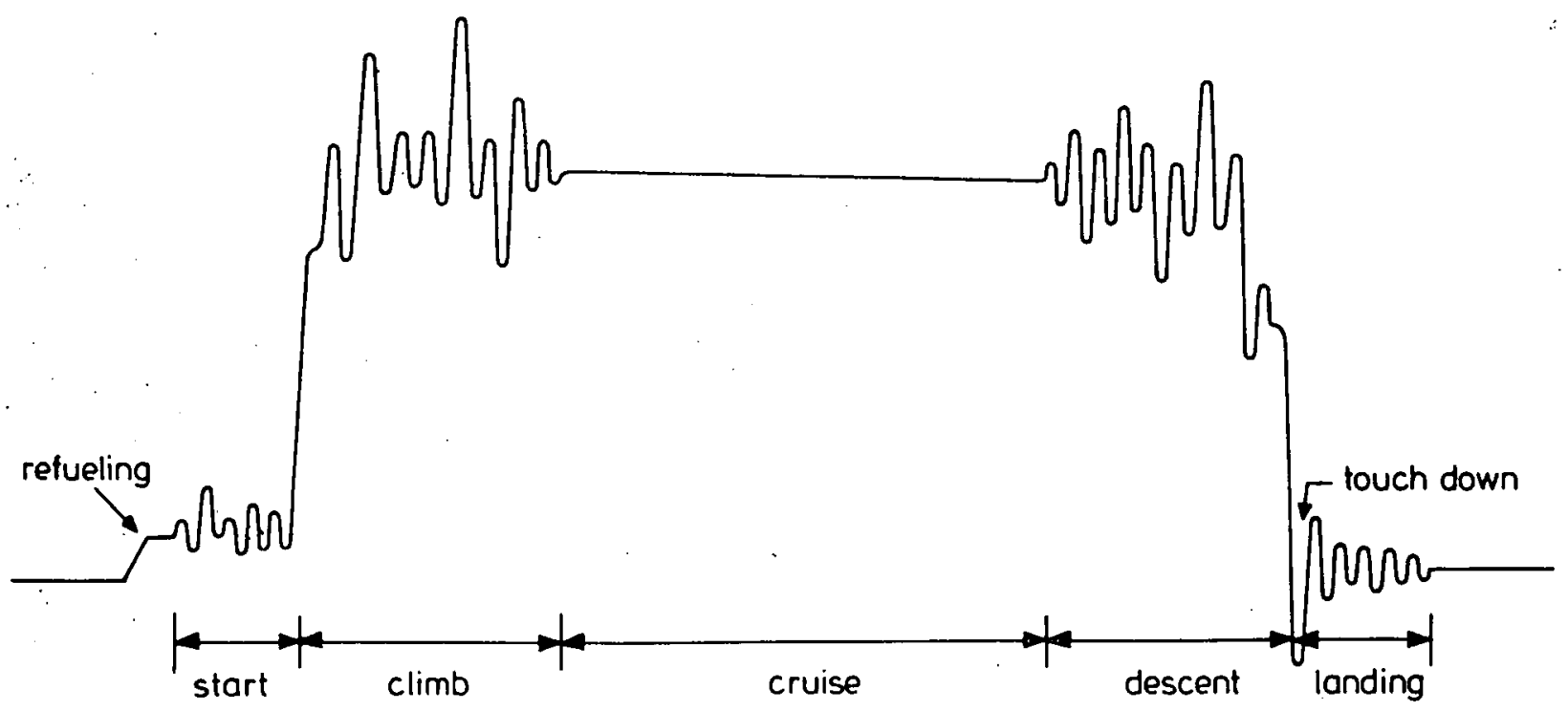

Figure 21: Schematic picture of an aircraft wing bending moment load history during one flight. Superposition of deterministic loads and. random loads. 
